\title{
Low Cost Polymer Heat Exchangers for Condensing Boilers
}

Dr. Thomas A. Butcher, Rebecca Trojanowski, George Wei, and Michael Worek

\author{
Sustainable Energy Technologies Department \\ Energy Conversion Group
}

\author{
Brookhaven National Laboratory \\ P.O. Box 5000 \\ Upton, N.Y. 11973-5000 \\ www.bnl.gov \\ submitted to: \\ National Oilheat Research Alliance \\ and
}

New York State Energy Research and Development Authority 


\begin{abstract}
Work in this project sought to develop a suitable design for a low cost, corrosion resistant heat exchanger as part of a high efficiency condensing boiler. Based upon the design parameters and cost analysis several geometries and material options were explored. The project also quantified and demonstrated the durability of the selected polymer/filler composite under expected operating conditions. The core material idea included a polymer matrix with fillers for thermal conductivity improvement. While the work focused on conventional heating oil, this concept could also be applicable to natural gas, low sulfur heating oil, and biodiesel- although these are considered to be less challenging environments. An extruded polymer composite heat exchanger was designed, built, and tested during this project, demonstrating technical feasibility of this corrosion-resistant material approach. In such flue gas-to-air heat exchangers, the controlling resistance to heat transfer is in the gas-side convective layer and not in the tube material. For this reason, the lower thermal conductivity polymer composite heat exchanger can achieve overall heat transfer performance comparable to a metal heat exchanger. However, with the polymer composite, the surface temperature on the gas side will be higher, leading to a lower water vapor condensation rate.
\end{abstract}




\section{Acknowledgements}

The authors would like to acknowledge the great input and help provided by many people in this project. This includes BNL research engineers Chris Brown and Yusuf Celebi. Throughout this project we worked closely with Dr. Miriam Rafailovich and Dr. Kai Yang at Stony Brook University. The Stony Brook team worked in parallel to develop new material options for thermally conductive polymers. Dr. Jon Longtin and Dr. William Worek, of Stony Brook University, also made significant contributions in the heat transfer area.

We would also like to acknowledge Dr. John Warren and Dr. Barbara Panessa Warren of BNL for their contributions in the SEM work. They provided great insights into the analysis of the materials.

We would like to provide a special acknowledgement to Jonathan Jurgaitis of International Polymer Engineering in Tempe, Arizona who took-on the challenge of extruding and coiling the heat exchanger. This task proved much more difficult than originally anticipated and Jonathan put a great amount of extra effort and creativity into accomplishing this.

Finally we would like to thank several students who made very significant contributions to different parts of this project. This includes Julian Tawfik, Changhoon Lee, Mikhail Kuchuk, and Fong Wong. 


\section{Table of Contents}

Acknowledgements.




\section{List of Figures}

Figure 1: CAD drawings of two heat exchanger geometries. Left, single helical coil. Right, double helical coil

Figure 2: Basic geometry of helical coil for terminology ................................................................... 4

Figure 3: Illustration of two heat exchangers geometries modeled using CFD..................................... 5

Figure 4: Results of a CFD simulation of the single row heat exchanger. Display is gas temperature (K).... 6

Figure 5: Single row heat exchanger, stream function plot. The left side of this figure shows a

recirculation pattern.

Figure 6: Gas radial velocity for single row case. Illustrating non-uniformity of gas flow through the heat exchanger

Figure 7: Results of CFD analysis for single row case- overall heat exchanger effectiveness vs. wall material thermal conductivity.

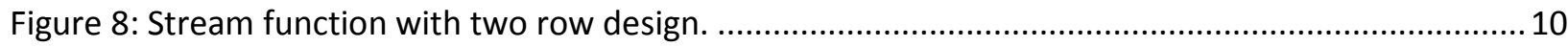

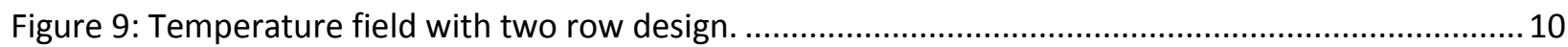

Figure 10: Radial velocity profile with two row design........................................................................ 11

Figure 11: Expanded view of temperature profile. Temperature scale units are in K............................... 11

Figure 12: Impact of wall thermal conductivity on effectiveness with the two row design. ....................12

Figure 13: Impact of wall thermal conductivity on effectiveness with two row design. Water temperature

$100 \mathrm{~F}$

Figure 14: Impact of wall thermal conductivity on tube surface temperature. Water temperature -100 F

Figure 15: Impact of thermal conductivity on effectiveness, outlet gas and wall temperatures...............16

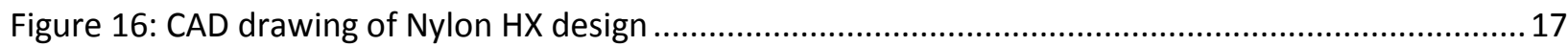

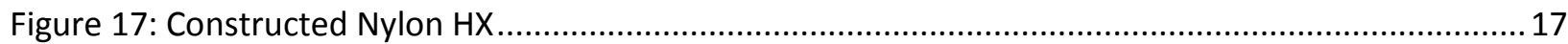

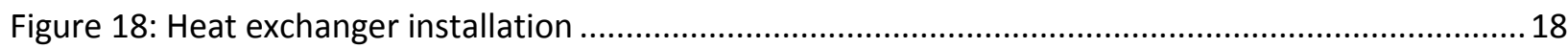

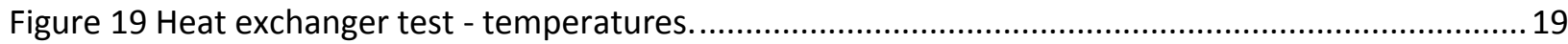

Figure 20: Candidate commercial conductive polymers - property comparison ....................................20

Figure 21: Preliminary design of polymer heat exchanger ................................................................... 21

Figure 22: Extruded helical coil of the thermally conductive polymer (coil spacing expanded for photo) 21

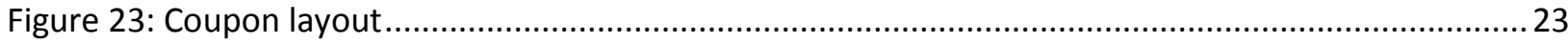

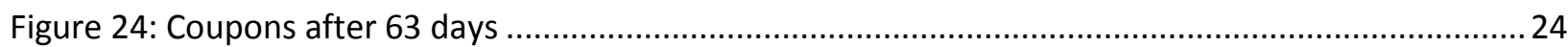

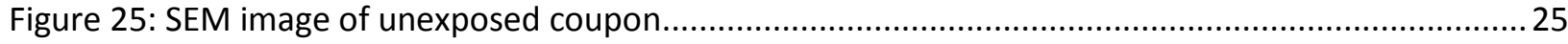

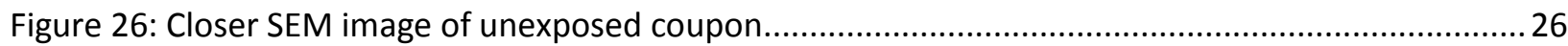

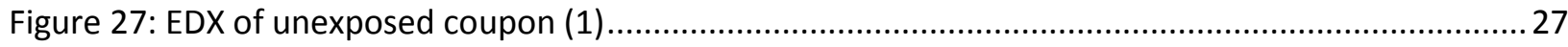

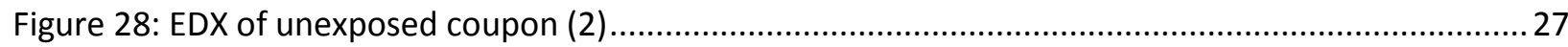

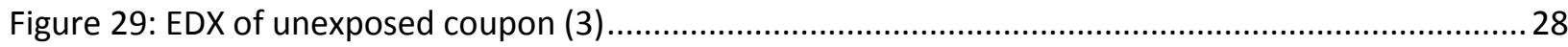

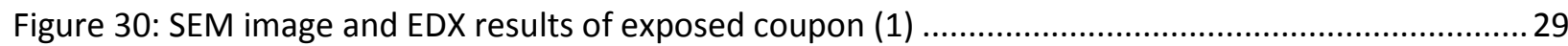

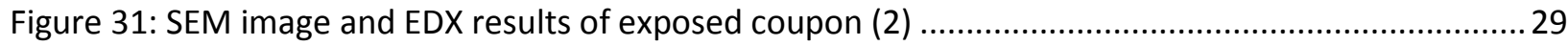

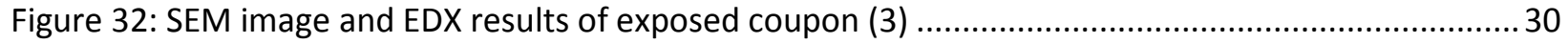

Figure 33: SEM image and EDX results of exposed coupon (4) ............................................................ 31

Figure 34: Overall SEM image of exposed coupon ................................................................................. 31 


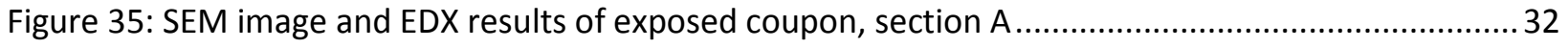

Figure 36: SEM image and EDX results of exposed coupon, section B ..................................................... 33

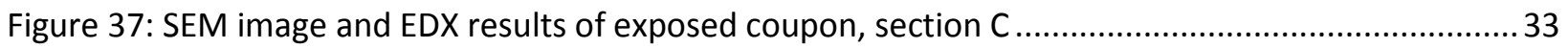

Figure 38 Illustration of polyethylene coated copper heat exchanger design .........................................36

Figure 39 Side view of polyethylene coated copper tubing ................................................................ 36

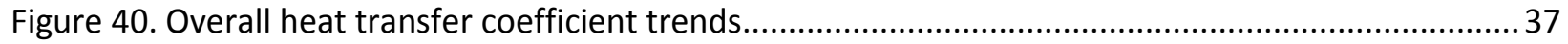




\section{List of Tables}

Table 1: Thermal Conductivity Comparison (at room temperature) ....................................................... 15

Table 2: Dimensions and Specifications of the Polymer Heat Exchanger............................................... 17

Table 3 Summary of Boiler Test Results with Thermally Conductive Polymer Heat Exchanger.................21

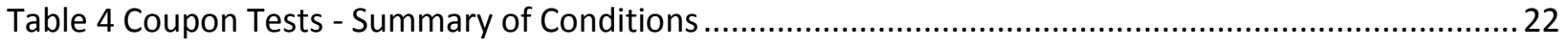

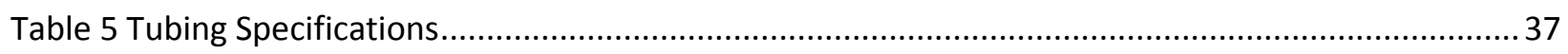

Table 6 Comparison of the Cost per Unit Volume of Polymer Composites and Alloys ............................ 38 


\section{Introduction}

Efforts in combustion technology have long focused on increasing system efficiency. In particular, condensing boilers achieve very high efficiency levels by recovering heat from the flue gas before it is discarded. The recovery of latent heat from the water vapor in the humid gas is a very important part of the total heat recovery but the condensate formed is corrosive leading to the need for expensive alloys in the heat exchanger.

The capital cost of the heat exchanger must not outweigh the economic benefit of the heat recovery. This project focused on the development of a low cost, polymer heat exchanger for this application. A simple example of the current use of polymers in boilers is concentric (air in/gas out) flue pipe arrangements now in common use with condensing hot water boilers. One German manufacturer includes a compact polymer air heater on a high efficiency, oil-fired boiler. The low cost of polymers provides a benefit; however the low thermal conductivity and size are of concern. Recent developments of thermally conductive polymer composites provide an alternative option.

The core material idea includes polymer matrix types with fillers for thermal conductivity improvement. The primary targeted polymer matrix at least initially in this work was polypropylene due to its temperature limitations and proven resistance to degradation in the harsh environment of flue gases. Alternative geometries were explored to minimize cost and increase the exchanger's effectiveness. While the work focused on conventional heating oil, this concept could also be applicable to natural gas, low sulfur heating oil, and biodiesel although these are considered to be less challenging environments.

\section{Materials of Construction}

The material(s) of construction used for heat exchangers depends on the fluids handled, process conditions (pressures, temperatures, etc.), a balance of initial cost against life expectancy and maintenance requirements. Factors affecting the heat exchanger life are excessive thermal stress, corrosion, creep, thermal fatigue and thermal shock. Ideally the heat exchanger should have a long service life and require little to no maintenance, in order to eliminate interruptions to the process. Materials that are susceptible to corrosion, scaling, and fouling lead to high maintenance costs and loss of productivity. Alternately, materials that retain mechanical and chemical properties often have a high initial cost.

One factor which impacts the heat exchanger's performance is the equipment's life against the aggressive environment of exhaust gases; therefore waste heat stream composition must be considered a constraint during the material selection. Many processes produce dirty or corrosive exhaust gases that will plug or attack heat exchangers ${ }^{1}$. Nitrogen, carbon dioxide, water vapor and small quantities of sulfuric, nitric, and hydrochloric acid are all present in boiler exhaust flue gases. Materials for thermal heat recovery equipment should exhibit resistance to high gaseous

\footnotetext{
1 “Energy Tips-Process Heating” US Department of Energy-Energy Efficiency and Renewable Energy (Nov. 2007)
} 
temperatures and corrosion due to the acidic environment yet the capital cost of the heat exchanger must not outweigh the economic benefit of the heat recovery.

Metals offer the advantage of processing ease, preferred ductility ranges, and properties (such as thermal conductivity), but are susceptible to corrosion from exhaust gases; therefore advanced and more costly materials are necessary in exhaust streams. Consequently, boiler manufacturers have introduced compact, polypropylene heat exchangers for concentric flue piping and, in a very few cases, preheating combustion air in boilers. Polypropylene offers resistance to degradation in the harsh flue gas environment and has higher temperature limitations compared to many other polymers (the maximum design temperature for this project was $350{ }^{\circ} \mathrm{F}$ ). Specifically, one boiler manufacturer in the U.K. has integrated a compact, polypropylene heat exchanger for preheating combustion air within their kerosene or biodiesel-fired boiler (Atlantic Boilers). Another, German manufacturer now also offers a boiler with a polymer air heating condensing section with a shell-and-tube design. Polymer heat exchangers have also reportedly been applied for flue gas heat recovery in utility power plants ${ }^{2}$.

As an alternative to all-polymer heat exchangers, polymer coatings could be considered. BNL has been very involved with Teflon covered condensing heat exchangers for larger commercial and industrial applications ${ }^{2}$ and also some developmental work on application to residential warm air furnaces. However, this approach was seen as expensive and concerns about performance under cyclic operation common for small residential appliances arose. From past studies, BNL had concluded polymer coatings were likely to survive in gas firing conditions but not the more acidic oil case.

\section{Stony Brook University Research}

Standard materials used for heat exchanger construction such as metals and ceramics are relatively expensive and corrode over time. Polymers on the other hand are often over looked as heat exchanger materials due to their low thermal conductivity. The Material Science department at Stony Brook University sought to development novel materials to address these problems. The group worked with new designs and materials that contained carbon black, carbon nanotubes, aluminum oxide, and graphene as additives in polypropylene. Unlike previous work, SBU sought to reduce the loading of additives to the polymer. Their goal kept the loading well under $20 \%$ to maintain some of the desirable mechanical properties of pure polymers such as processing ease. The group was able to disperse the additives in the polymer matrix, achieving an ideal blend and percolation to achieve a thermal conductivity value of $1.5 \mathrm{w} / \mathrm{mK}$ compared to the typical value of 0.23 seen for pure polypropylene. Due to project timing the materials developed by the Stony Brook team were not used in actual heat exchangers built. A summary of their accomplishments is provided in a journal publication, included as Appendix I to this report.

\footnotetext{
${ }^{2}$ Zaheed, L. and Jachuck, R.J.J., "Review of polymer compact heat exchangers with special emphasis on polymer film units", Applied Thermal Engineering, 24, (2004), pp. 2323-2358.
} 


\section{Proposed Exchanger Design}

Extruded-metal heat exchanger designs with welded headers are common and may be the best approach for waste heat recovery, however spiral tube (round or rectangular cross section) geometries may offer lower manufacturing cost and are also more recently available. Another advantage found throughout literature is higher heat transfer rates have been obtained from helical coil designs compared to straight tubes. The spiral tube approach was selected for this project as the design could be produced using an extrusion process. An advantage of this approach is that it involves no or a minimal amount of connections which could be a concern for water leakage. The spiral tube geometry has been successfully used now with some compact, alloy condensing heat exchangers.

The proposed exchanger design had the limitations of fitting in an eight inch exhaust flue pipe and the ability to withstand temperatures up to $350{ }^{\circ} \mathrm{F}$. Two geometries were explored; both involving coils of round cross section tubing. One was a single row and the second is a double row, shorter heat exchanger. Both geometries are illustrated in Figure 1.
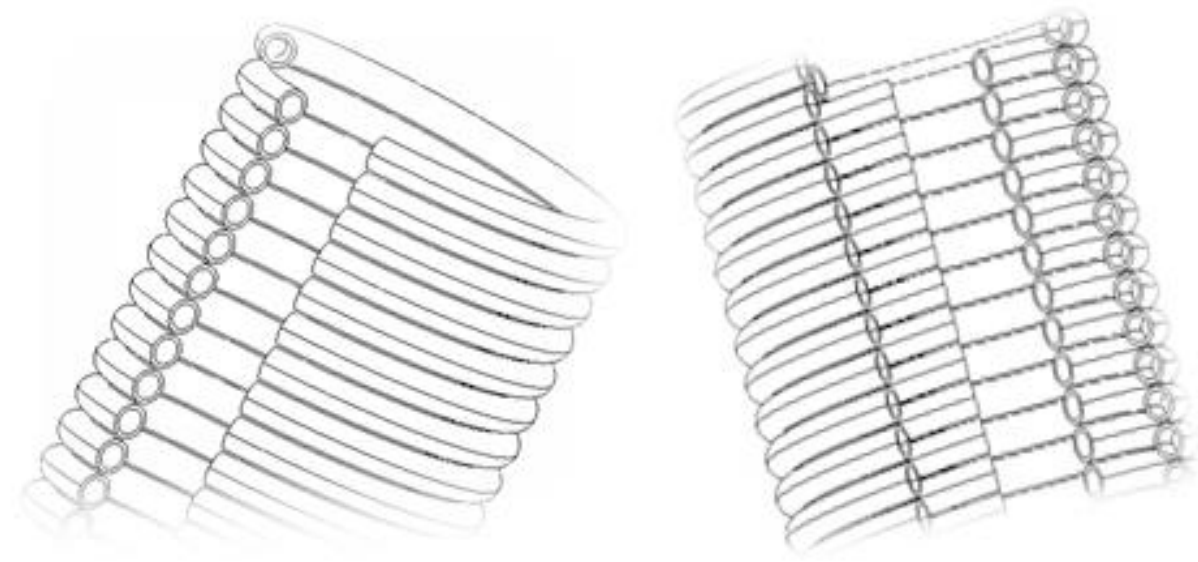

Figure 1: CAD drawings of two heat exchanger geometries. Left, single helical coil. Right, double helical coil.

Figure 2 below provides a schematic of the helical coil to better understand the terminology. The tube has inner and outer diameters of $r$ and $R$, respectively. The value of $R$ minus $r$ can be related to the thickness of the tubing. The coil diameter is represented by $\mathrm{C}$ (measured between the centers of the tubes). The distance between two adjacent turns is referred to as the pitch, $\mathrm{P}$. 


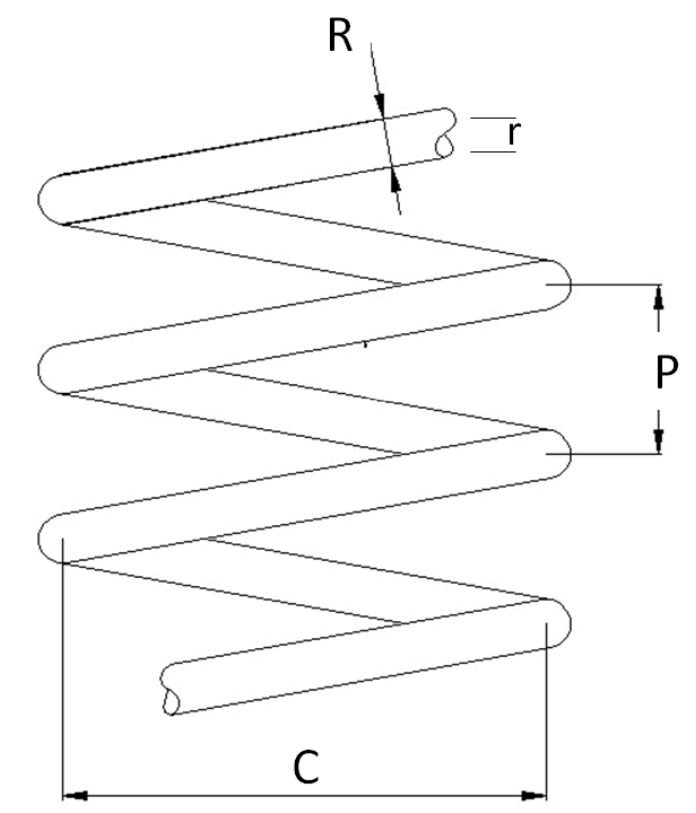

Figure 2: Basic geometry of helical coil for terminology

Through a computational fluid dynamics (CFD) analysis, the materials thermal conductivity was evaluated on the overall performance for a given heat exchanger geometry. The detailed CFD studies were completed for the selected geometries over a wide range of material thermal conductivities. CFD studies were done using Ansys/Fluent - a commercial software product. A primary goal of this analysis was to evaluate the impact of the wall material thermal conductivity on the overall performance.

The first geometry examined, left side of Figure 3, was a single row, coiled tube. The second geometry was a double row with the same total tube length as for the single row case. In all cases the analysis was done assuming a firing rate of $0.65 \mathrm{gph}$, an excess air level of $25 \%$, and exhaust gas leaving the boiler and entering the heat exchanger at $300^{\circ} \mathrm{F}$. The analysis was done for sensible heat transfer only as Fluent does not handle condensation heat transfer and condensate flow without use of custom routines. A k- $\varepsilon$ turbulence model was used in an axisymmetric, two-dimensional model. With this approach only half of the flow fields illustrated in Figure 3 was analyzed. 

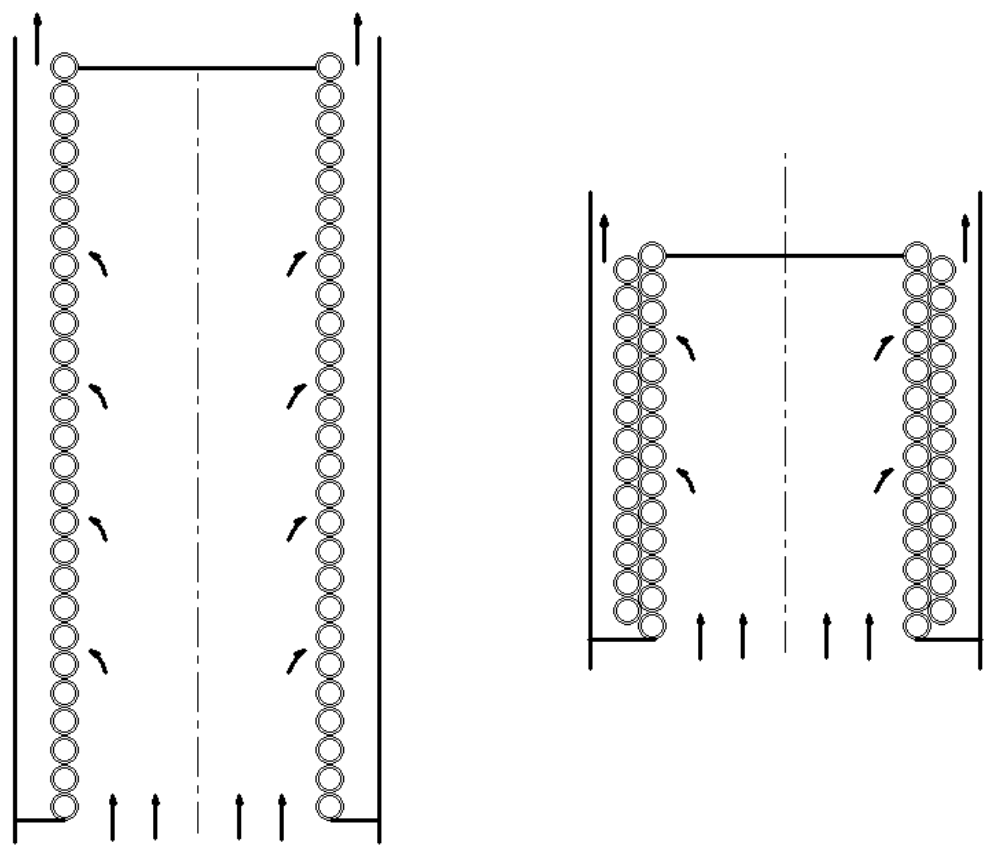

Figure 3: Illustration of two heat exchangers geometries modeled using CFD.

For both heat exchangers the tube diameter was $1 / 2$ " and the gap between adjacent tubes was 1 $\mathrm{mm}$. The single row heat exchanger had 27 coils and a length of a little more than $1 \mathrm{ft}$. Figure 4 shows the results of one analysis of the single row case. Here the parameter illustrated is gas temperature in degrees K. Fluent's default case is SI units and absolute temperature. The heat exchanger is sideways in this illustration and hot gas from the boiler enters from the left. Only one half of the heat exchanger is shown. Gravity was turned on for these studies but, in Fluent, there is the option to have gravity in any direction. In this case gravity acts to the left, so it is really a vertical flow and axis. 


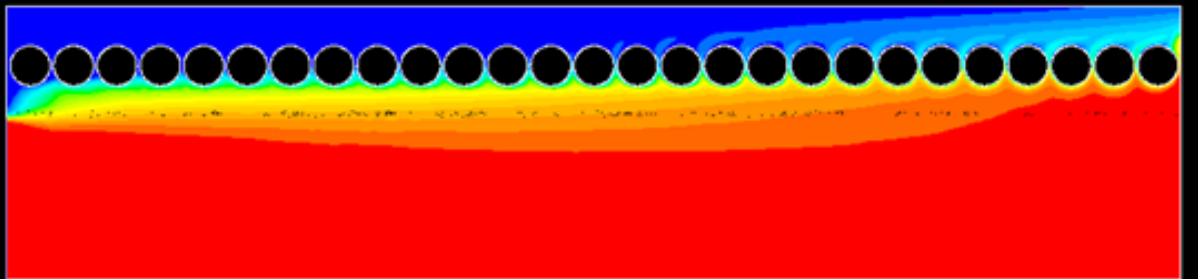

Figure 4: Results of a CFD simulation of the single row heat exchanger. Display is gas temperature (K)

There were several options for boundary conditions on the heat exchanger. For the first few runs it was assumed that the tube surface temperature was fixed. Following this a convective boundary condition was assumed. Here the temperature of the fluid flowing through the tube was fixed as was the inside convective heat transfer coefficient, the thickness of the wall of the tube, and the thermal conductivity of the tube material. This last property was particularly important because it allowed an analysis on the effect of thermal conductivity on overall heat exchanger performance. For all cases here the wall thickness is assumed to be $1.5 \mathrm{~mm}$.

Examination of the results of runs with the single row heat exchanger showed that there was a recirculation zone out through the tube row and then back into the center section on the left (inlet) side of the heat exchanger. This is illustrated in a stream function plot for this case, Figure 5 . 


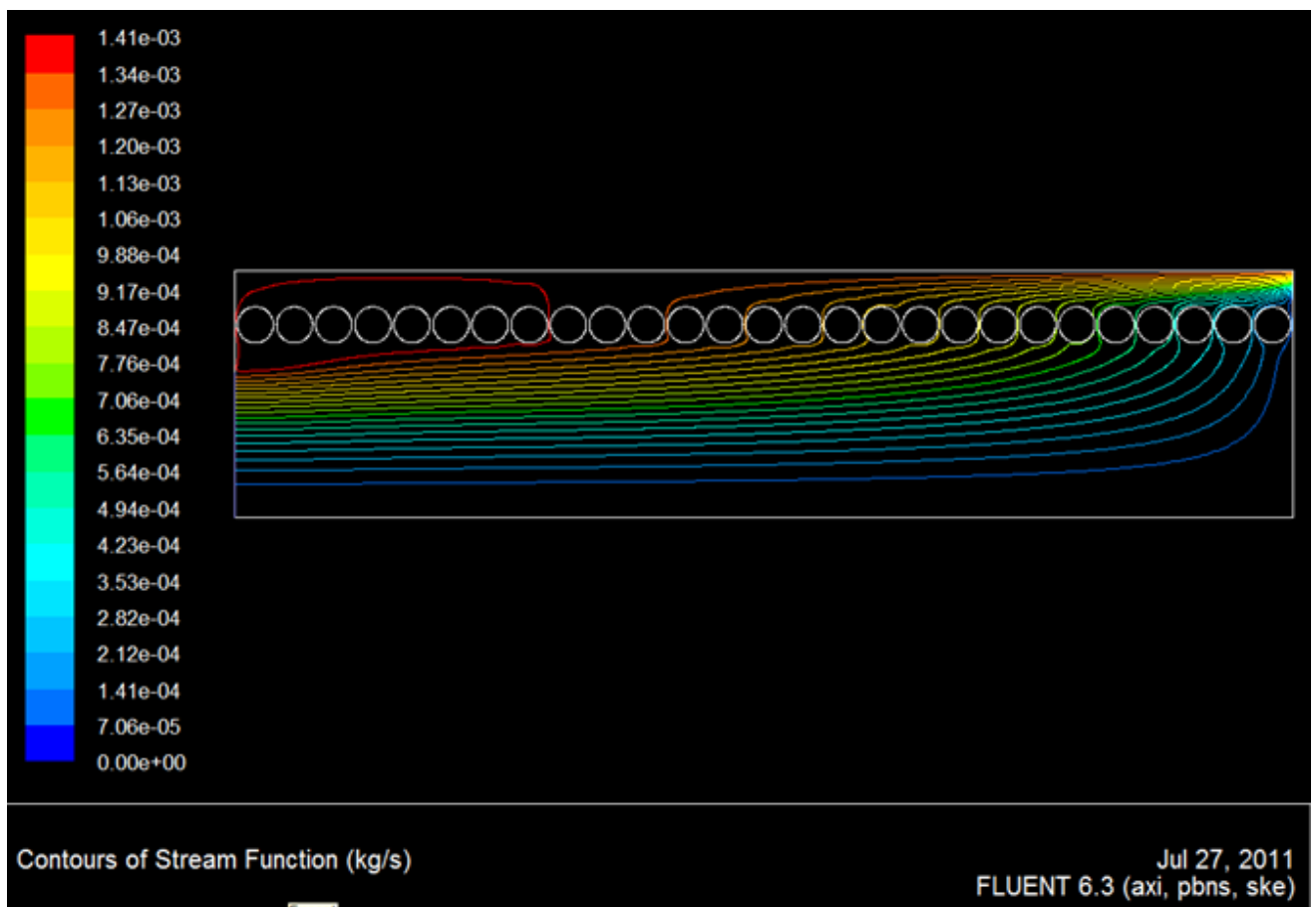

Figure 5: Single row heat exchanger, stream function plot. The left side of this figure shows a recirculation pattern.

Another illustration of this situation is provided in Figure 6 which is a plot of the radial velocity (out through the tubes). What is plotted here is the radial velocity along a line tangent to the outer edges of all of the tubes. On the right side the velocity is the highest and most flow passes through this side. On the left side the velocity is negative indicating flow is going back in through the heat exchanger tubes. 


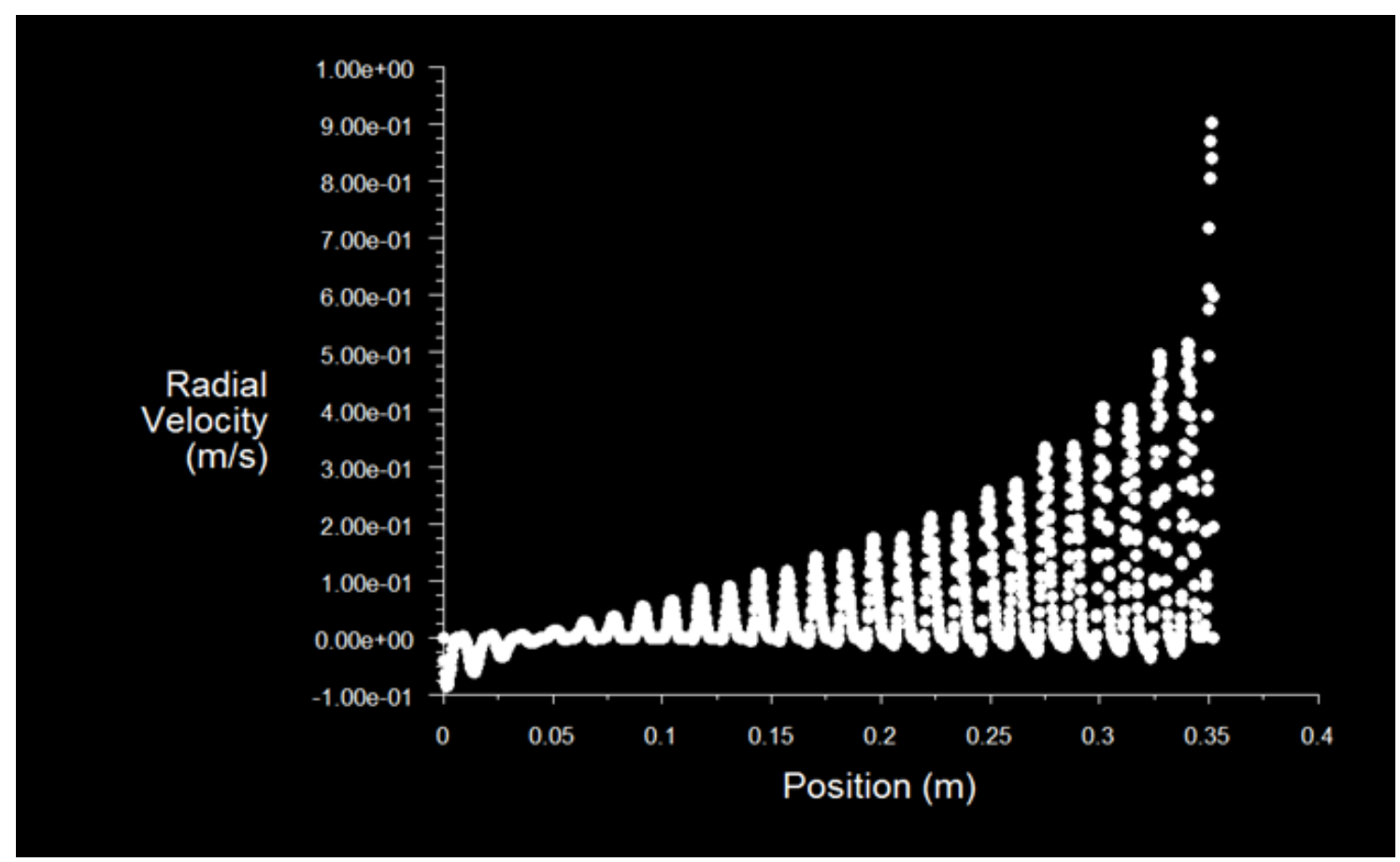

Figure 6: Gas radial velocity for single row case. Illustrating non-uniformity of gas flow through the heat exchanger.

This result occurred because the pressure drop across the tube row was simply too low $(\sim 0.012$ inches of water based on CFD runs). With this type of flow pattern the left side (referring to Figures 2 and 3 ) of the heat exchanger is not contributing to the overall performance.

With the single row design some exploration was done regarding the effect of the material's thermal conductivity on overall heat exchanger effectiveness which is defined as heat transfer divided by maximum possible heat transfer. This maximum possible heat transfer would occur if the exhaust gas leaving were the same as the fixed temperature of the circulating water. The inside convective heat transfer coefficient inside of the tube for this analysis was assumed to be very high $-500 \mathrm{~W} / \mathrm{mK}$ - simply to eliminate this as a factor in overall performance. For this, thermal conductivities ranging from $0.25 \mathrm{~W} / \mathrm{mK}$ (an example unmodified plastic) to 16.3 (a stainless steel) were explored. Figure 7 shows calculated effectiveness vs. wall thermal conductivity. 


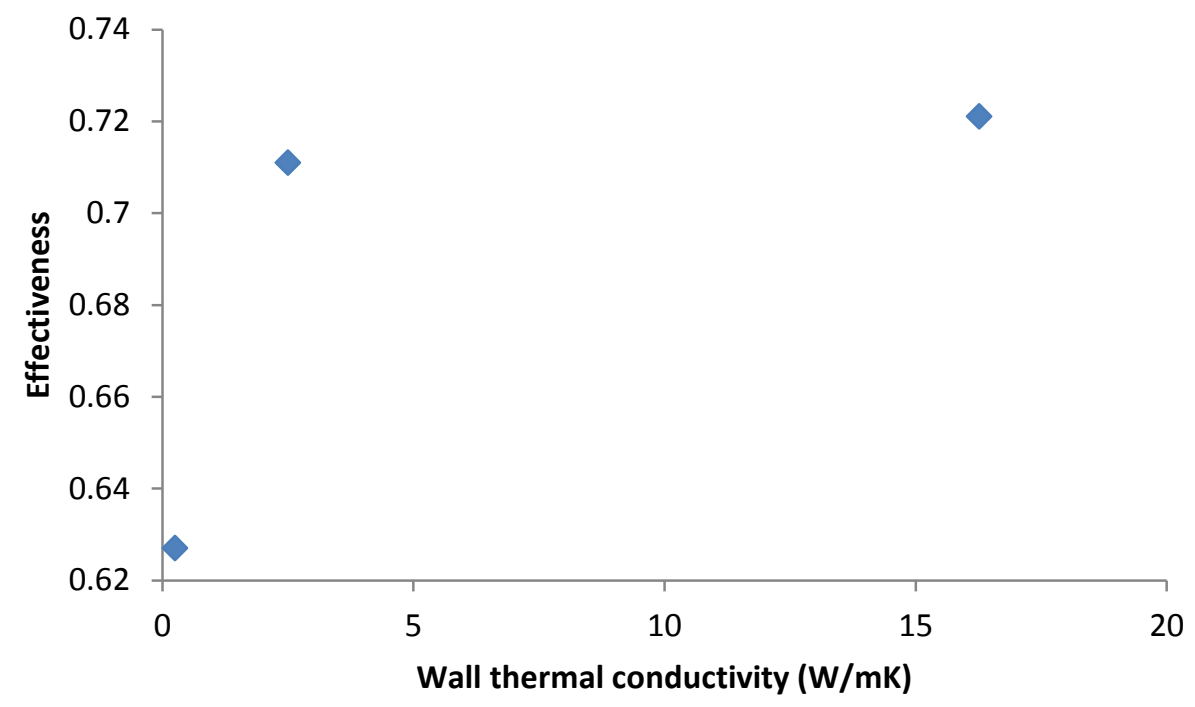

Figure 7: Results of CFD analysis for single row case- overall heat exchanger effectiveness vs. wall material thermal conductivity.

The results in Figure 7 suggest that the benefits of increased wall material thermal conductivity are most significant in the range of $0.25 \mathrm{~W} / \mathrm{mK}$ (unmodified plastic) to roughly 2.5 . These results indicate increases in thermal conductivity don't significantly improve heat exchanger performance since the controlling resistance for heat transfer becomes the gas-side convection film resistance. It should be noted that this conclusion about the relative importance of wall material conductivity and the convective heat transfer coefficient is dependent upon the geometry. In a higher pressure drop, more compact heat exchanger design the convective heat transfer coefficient will be higher and the sensitivity of the effectiveness to wall material conductivity greater.

The concept for the two-row heat exchanger design (right side of Figure 3) was developed in response to the reverse flow situation noted for the single row case. The double row heat exchanger had the same number of "loops" in the coil but some were simply relocated to create the second row. The total surface area was similar to the single row case but the pressure drop was expected to be higher. The uniformity of flow through the heat exchanger therefore would also be higher. The spacing between the first and second rows was arranged so that the minimum flow area has a spacing of $1 \mathrm{~mm}$ which was the same as for the spacing between the tubes in each row.

With the two row design the flow uniformity was much better, the overall effectiveness is higher, and the pressure drop was higher (0.0274 inches of water).

For the two row geometry, Figure 8 shows the stream functions and it can be noted that the reverse flow zone has been eliminated. Figure 9 shows the temperature field. Figure 10 is a plot 
of the radial velocity and this can be compared the results show in Figure 6. The improved uniformity of flow is evident through this comparison.

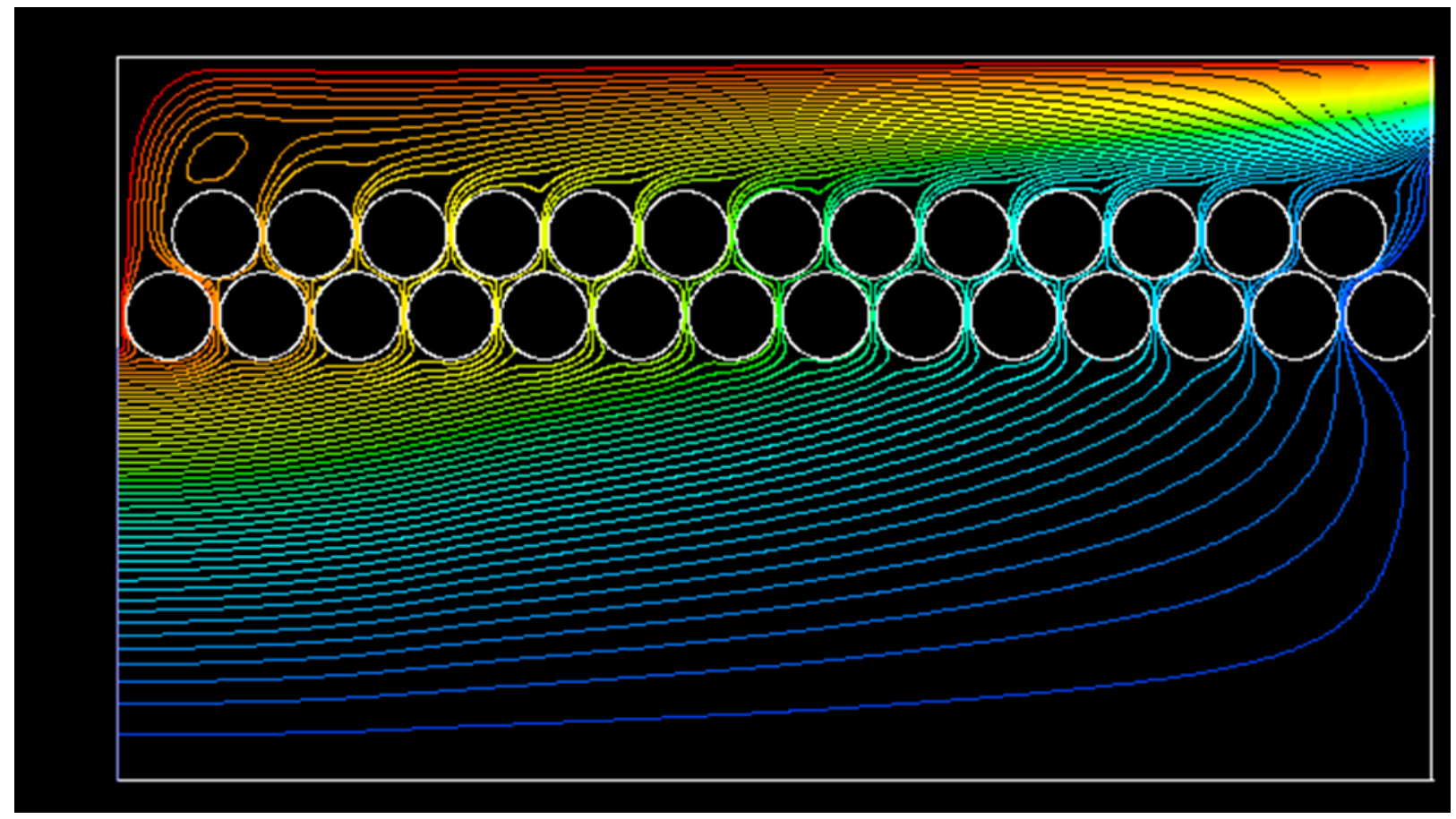

Figure 8: Stream function with two row design.

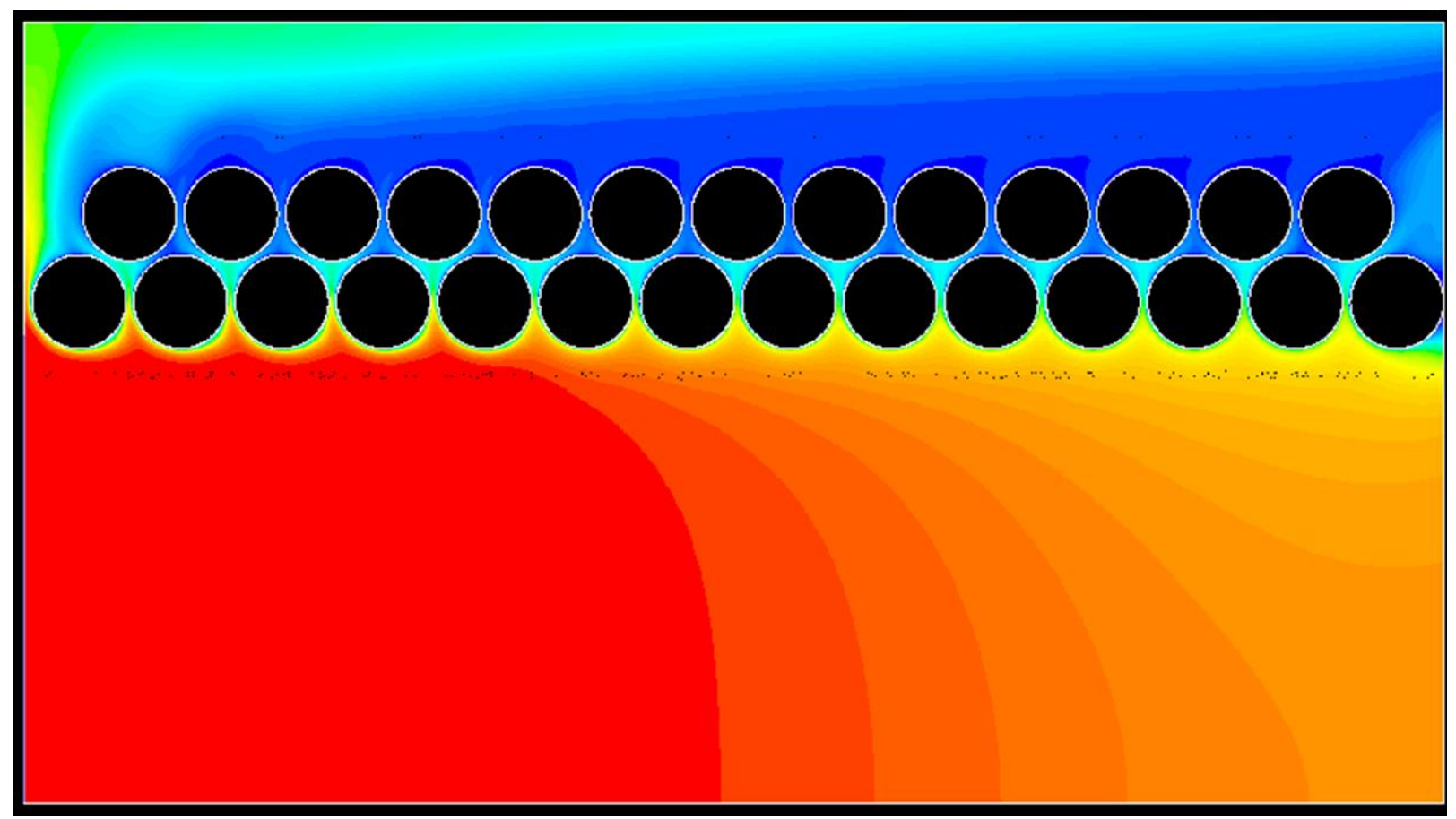

Figure 9: Temperature field with two row design. 


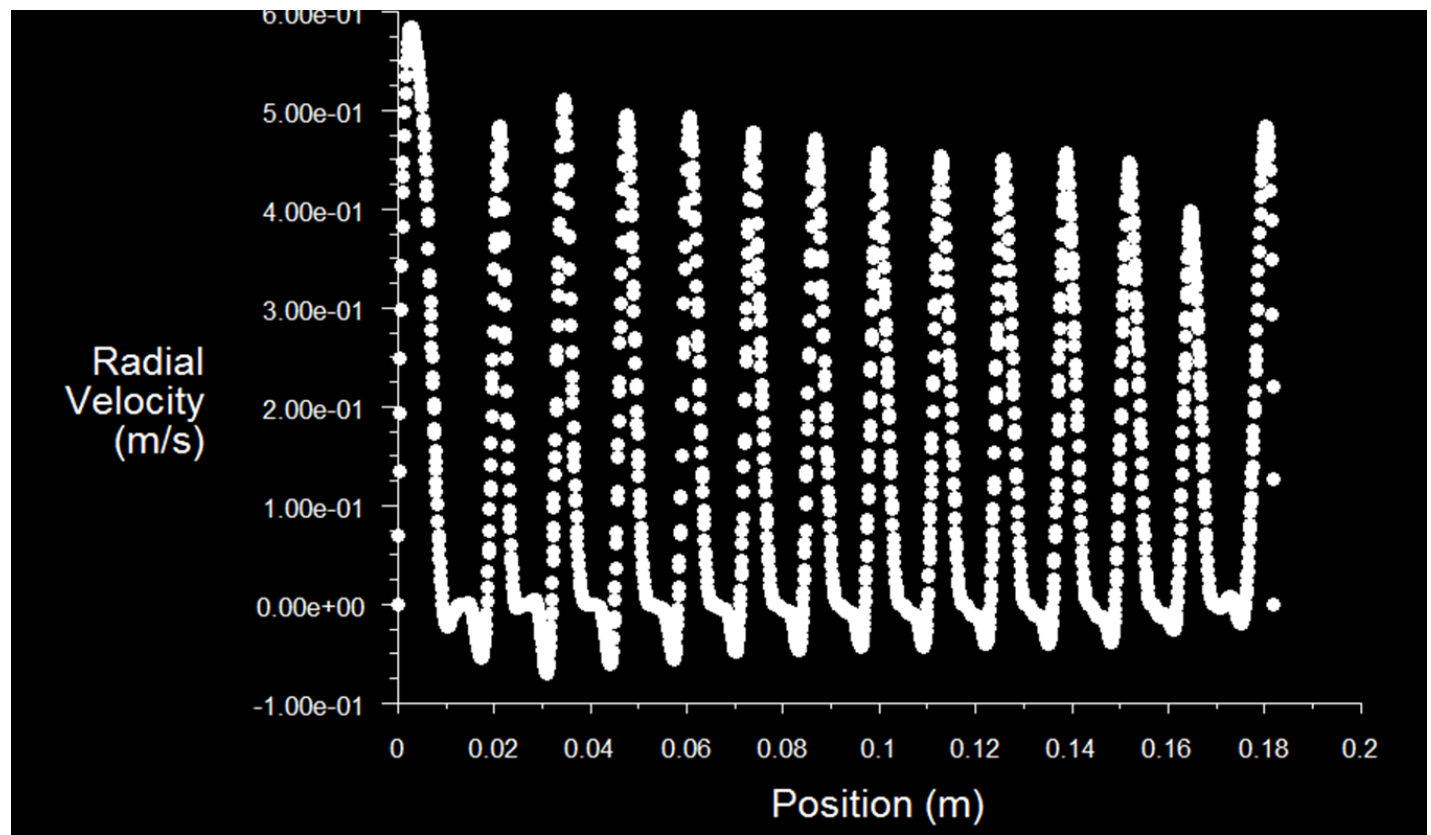

Figure 10: Radial velocity profile with two row design.

Figure 11 shows an enlarged view of the temperature profile through part of the heat exchanger.

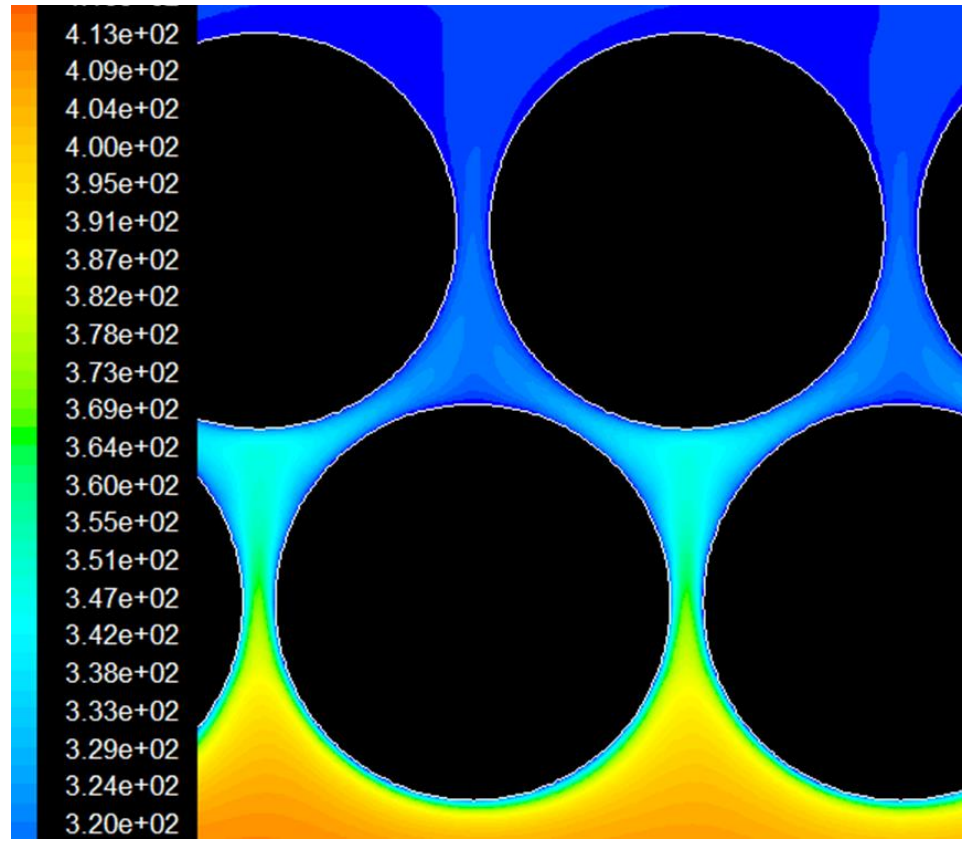

Figure 11: Expanded view of temperature profile. Temperature scale units are in $\mathrm{K}$ 
Figure 12 shows the impact of the heat exchanger wall material thermal conductivity on the heat exchanger effectiveness and, like in Figure 7, the thermal conductivity only needs to be increased from 0.25 to about $2.5 \mathrm{~W} / \mathrm{mK}$ to approach the performance of stainless steel $(16.5 \mathrm{~W} / \mathrm{mK})$.

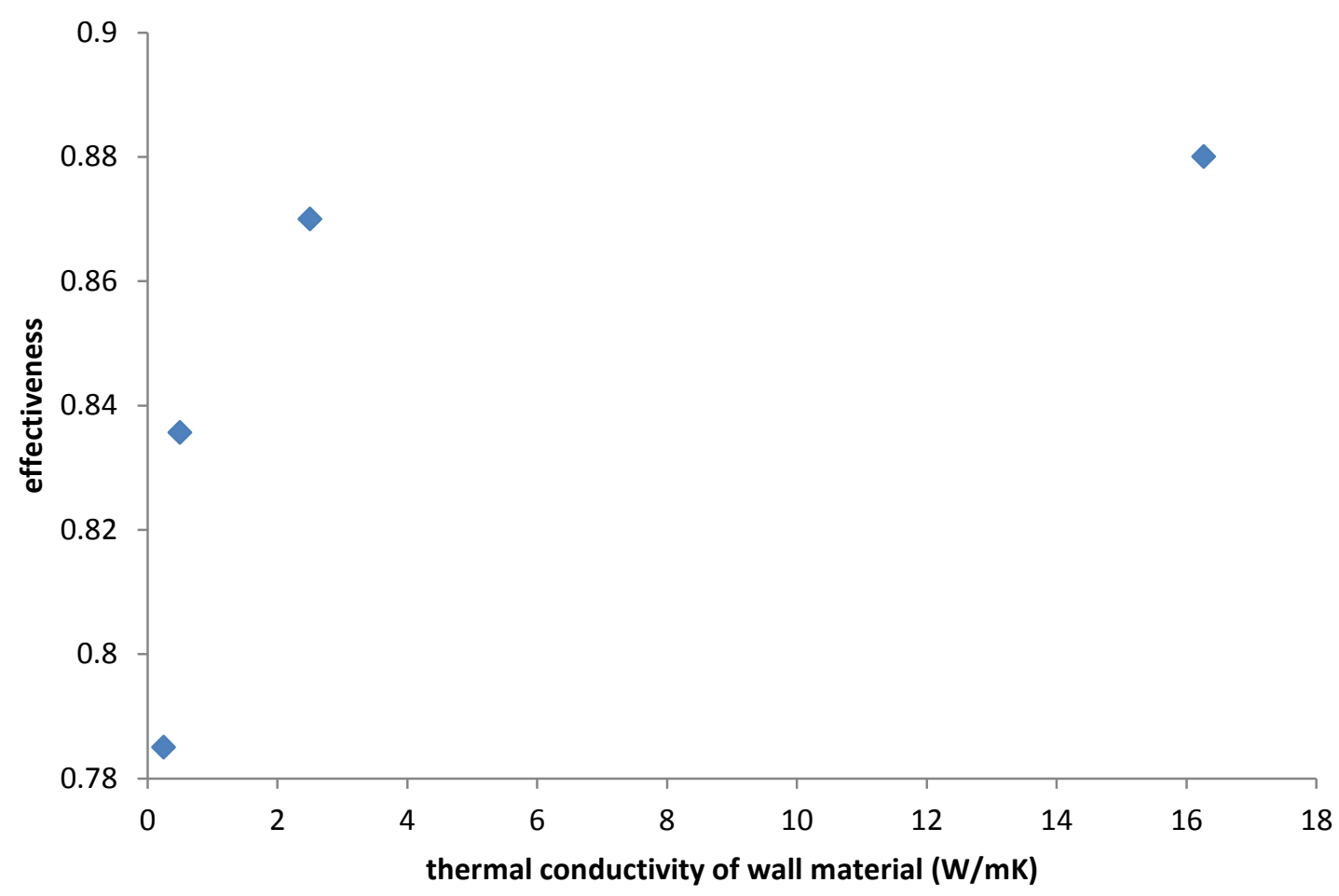

Figure 12: Impact of wall thermal conductivity on effectiveness with the two row design.

An additional series of runs was done with the two row design at a lower water temperature $100{ }^{\circ} \mathrm{F}$.

This is well below the dewpoint of water vapor in the flue gas with oil firing. The purpose was to evaluate the impact of reduced thermal conductivity of the wall material on the tube surface temperature. Based on our prior experience at BNL condensation will start when the wall temperature is below about $117{ }^{\circ} \mathrm{F}$. Figure 13 shows the impact of wall conductivity on effectiveness with this water temperature and results are similar to those shown in Figure 12. Note that runs have been done for more thermal conductivity conditions. 


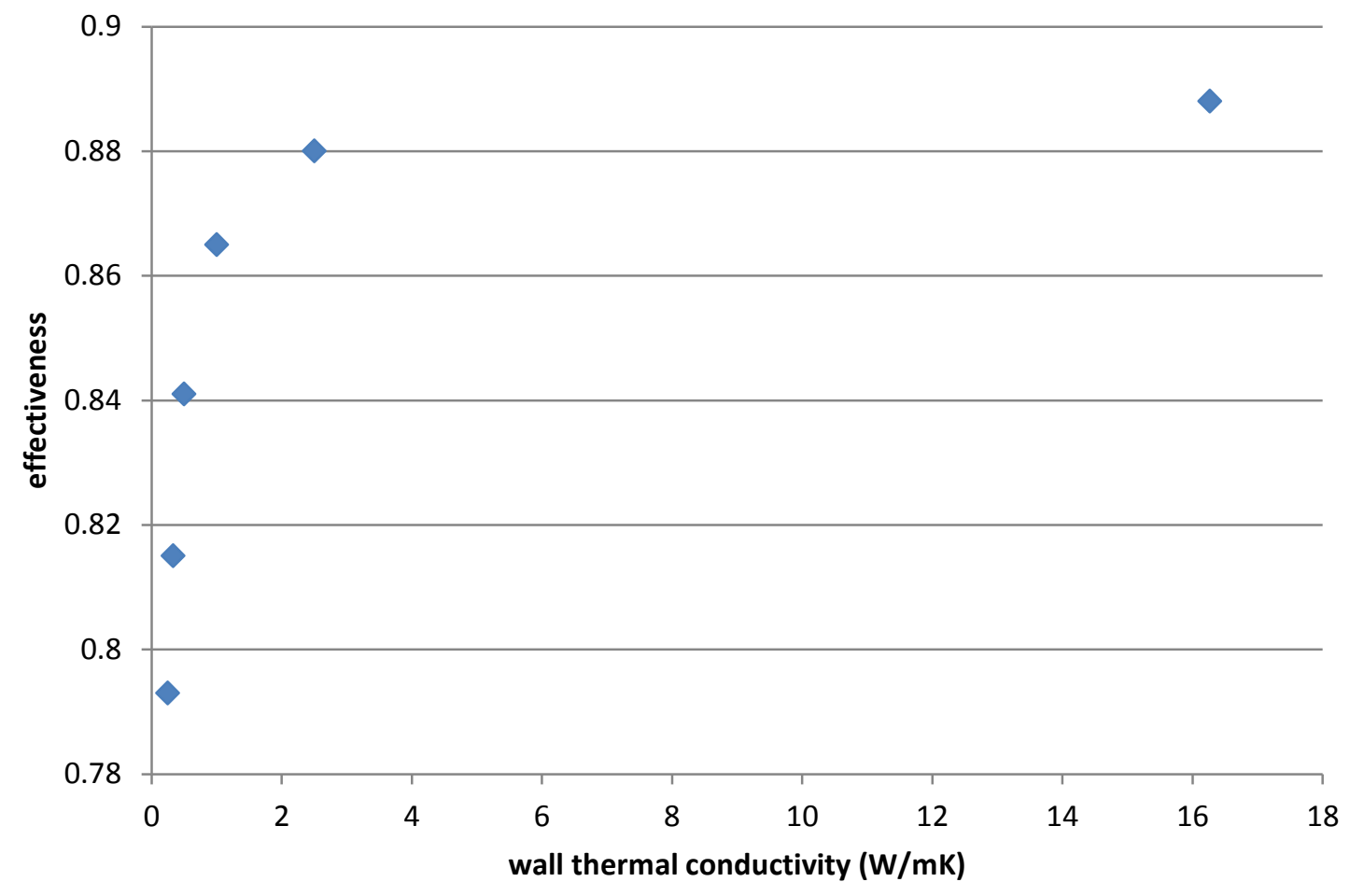

Figure 13: Impact of wall thermal conductivity on effectiveness with two row design. Water temperature $100 \mathrm{~F}$

Figure 12 shows the effect of wall thermal conductivity on tube surface temperature and this illustrates an important consideration for materials with lower thermal conductivity - there will be less condensation. This could be considered a strong advantage in design in the sense that lower thermal conductivity will enable higher efficiencies to be achieved without condensation i.e. through sensible heat recovery only. Without condensation oil-fired boiler efficiencies up to $92 \%$ can be achieved. With gas, which has a higher flue gas water content, the maximum achievable efficiency without condensing is about $88 \%$.

To illustrate how this might be used in a design: assuming a wall material thermal conductivity of $1.0 \mathrm{~W} / \mathrm{mK}$ ( $4 \mathrm{X}$ that of the base polymer). With the $100{ }^{\circ} \mathrm{F}$ return water temperature the tube surface would be at $117.7{ }^{\circ} \mathrm{F}$ and condensation would not occur. The heat exchanger effectiveness here would be 0.865 which is not much lower than the effectiveness achieved with a stainless steel tube -0.888 . Condensation would occur with the stainless steel, but not with the polymer tube. 


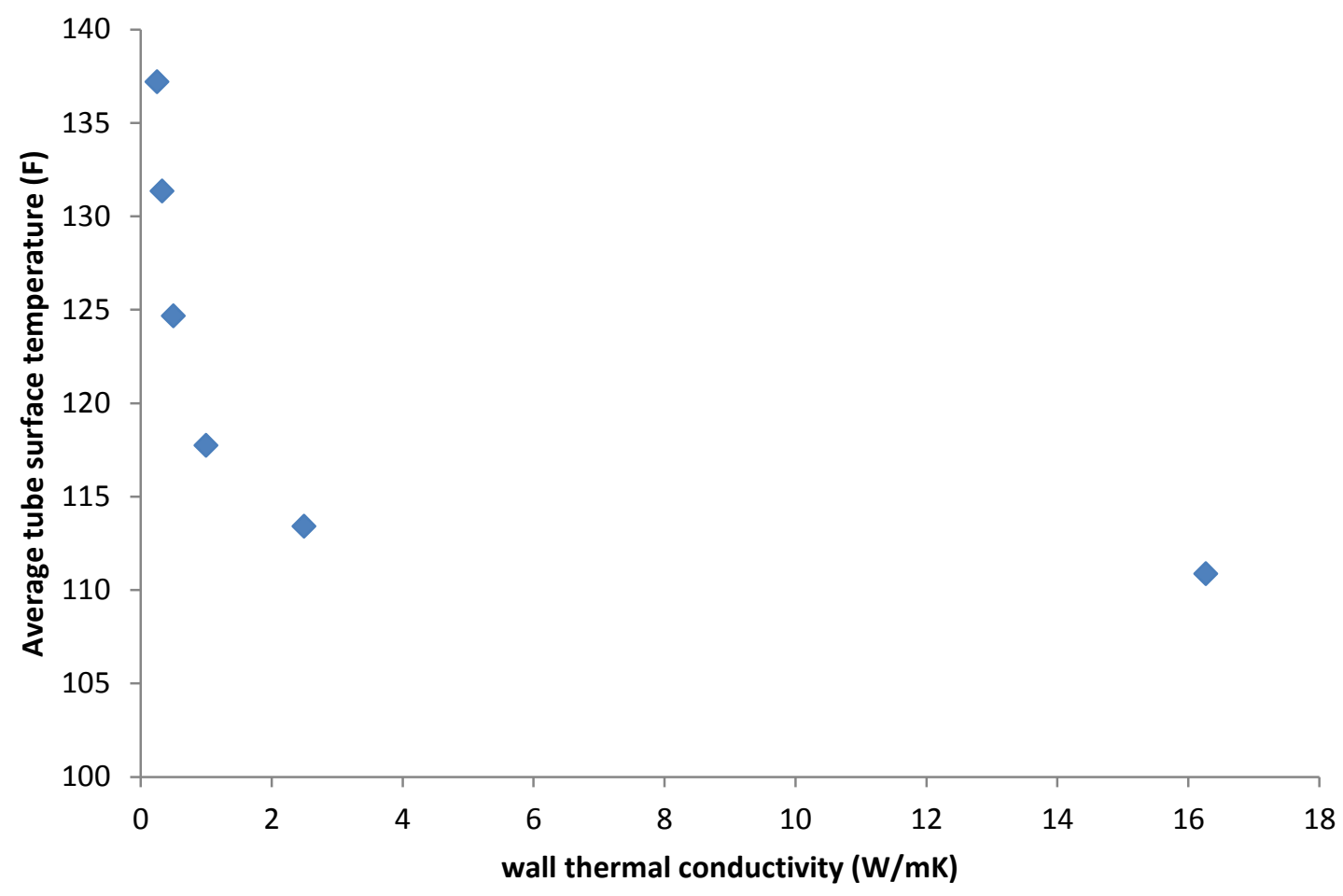

Figure 14: Impact of wall thermal conductivity on tube surface temperature. Water temperature $-100 \mathrm{~F}$

\section{Impact of Thermal Conductivity}

While the cost of polypropylene makes for an attractive option, one concern is the low thermal conductivity and its impact on the overall heat transfer performance and size. As significantly increasing the heat exchanger size is seen as an undesirable option, the thermal conductivity of the selected material is important. This concern is compounded by lower tensile strength which would require thicker heat exchanger "walls". The overall heat transfer coefficient in a flue gas heat exchanger depends on the material conductivity but also on the convective film coefficients. In larger, low pressure drop, condensing heat exchanger sections the gas film coefficient is "controlling" and low thermal conductivity of the plastic material would not lead to a large increase in required area. With more compact, higher pressure drop designs the low conductivity would translate into a larger required area.

The low cost and corrosion resistance of polymers provides a benefit; however the low thermal conductivity and size are of concern. Recent developments of thermally conductive polymer composites provide an alternative option. The addition of nanoparticles and other fillers as thermal conductors are able to increase the thermal conductivity (to 15 times or greater) of pure 
polymers $^{3,4}$. With the recent developments of high thermal conductivity polymer composites, heat exchangers constructed of these modified polymers now provide an alternative option to expensive alloys and ceramics.

Table 1, below provides a comparison of pure polypropylene, thermally conductive polypropylene and other common materials for heat exchanger construction. From the CFD analysis done, the impact of the low thermal conductivity of the polymer was found to be very low as the gas-side convective coefficient was clearly controlling in this specific case. Figure 15 illustrates the effectiveness, outlet temperature and wall temperature as a function of tube thermal conductivity. The results indicate thermal conductivity values of stainless steel do not need to be achieved for similar heat transfer performance. An increase in thermal conductivity from 2 to $5 \mathrm{X}$ is really all that is needed; therefore a low value thermal conductivity value of approximately $2.5 \mathrm{~W} / \mathrm{mK}$ would be adequate.

Table 1: Thermal Conductivity Comparison (at room temperature)

\begin{tabular}{|c|c|}
\hline Material & Thermal Conductivity (W/mK) \\
\hline Polypropylene & 0.22 \\
\hline Polypropylene with 30\% talc filler & 2.5 \\
\hline Stainless steel & 16 \\
\hline Cast iron & 55 \\
\hline Aluminum & 250 \\
\hline
\end{tabular}

\footnotetext{
${ }^{3}$ Weidenfeller, B. Höfer, M., and Schilling, F.R., "Thermal conductivity, thermal diffusivity, and specific heat capacity of particle filled polypropylene”, Composites: Part A: Applied Science and Manufacturing, 35, (2004), pp. 423-429.

${ }^{4}$ Enomoto, K. et. al., "Effect of filler orientation on thermal conductivity of polypropylene matrix carbon nanofiber composites", Japanese Journal of Applied Physics, 44.27 (2005), pp. 888-891.
} 


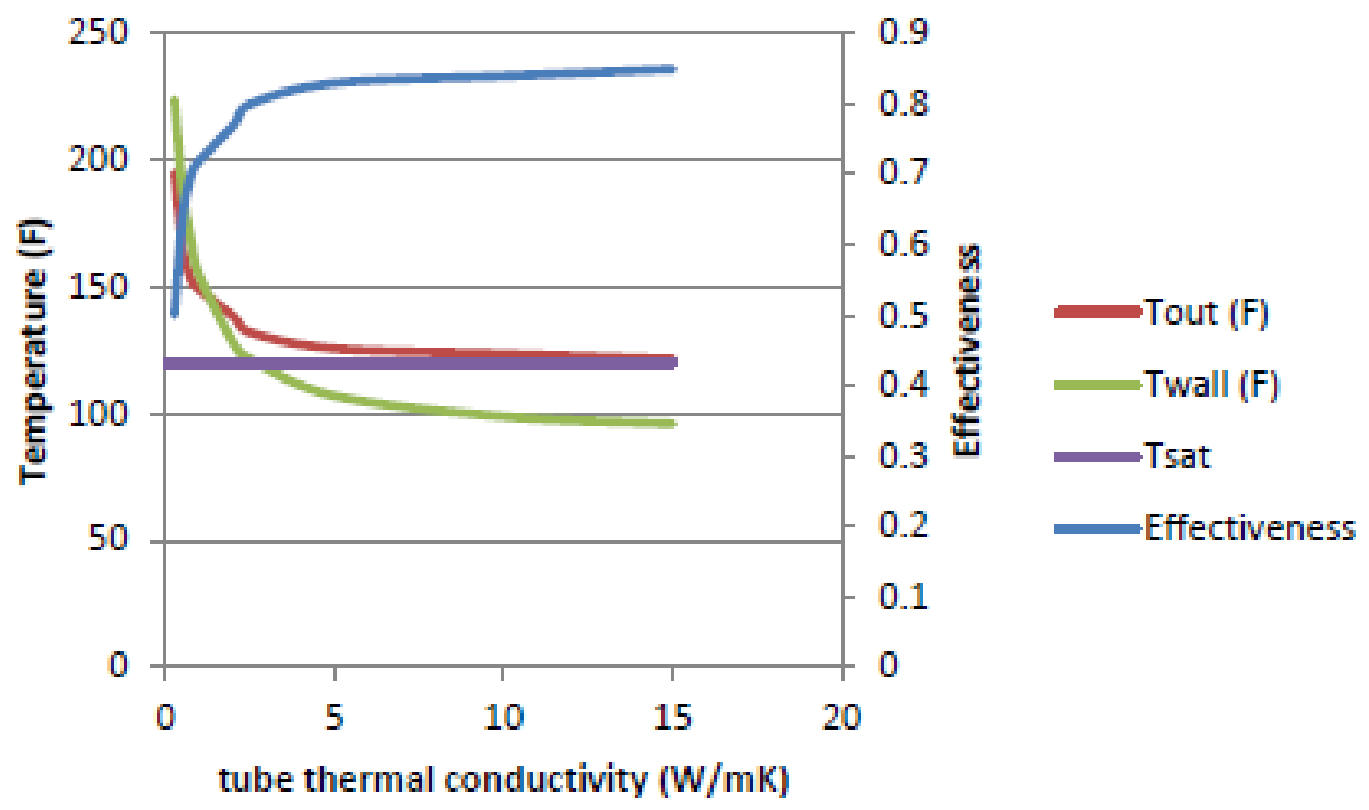

Figure 15: Impact of thermal conductivity on effectiveness, outlet gas and wall temperatures

\section{Experimental}

\section{Exchanger Prototype}

Based on the findings from the CFD studies, a pure polymer heat exchanger was designed and constructed. To determine the success of the design, the first prototype was constructed of Nylon-12, offering a very low thermal conductivity value, approximately $0.25 \mathrm{~W} / \mathrm{mK}$. The goal of this early stage was to validate the CFD model, demonstrate the design geometry, and test for major design failure/flaws.

To achieve the $1 \mathrm{~mm}$ spacing, Buna O-rings were spaced along each coil. During the construction of the heat exchanger, it was also understood one continuous coil was not feasible due to the change in rotation; therefore two coils were used and connected using a $180^{\circ} \mathrm{U}$-bend. To maintain the structure of the exchanger, stainless steel threaded rods were placed in the center and drilled into the top and bottom plates. To avoid direct contact of the stainless steel to the Nylon, high temperature silicone glue was painted on. The top and bottom plates were constructed of stainless steel as well and were also coated with a high temperature glue to avoid direct metal to plastic contact. Figure 16 shows a computer aided design (CAD) drawing of the Nylon heat exchanger. Figure 17 show the actual constructed exchanger. The dimensions of the exchanger may also be seen in Table 2 . 


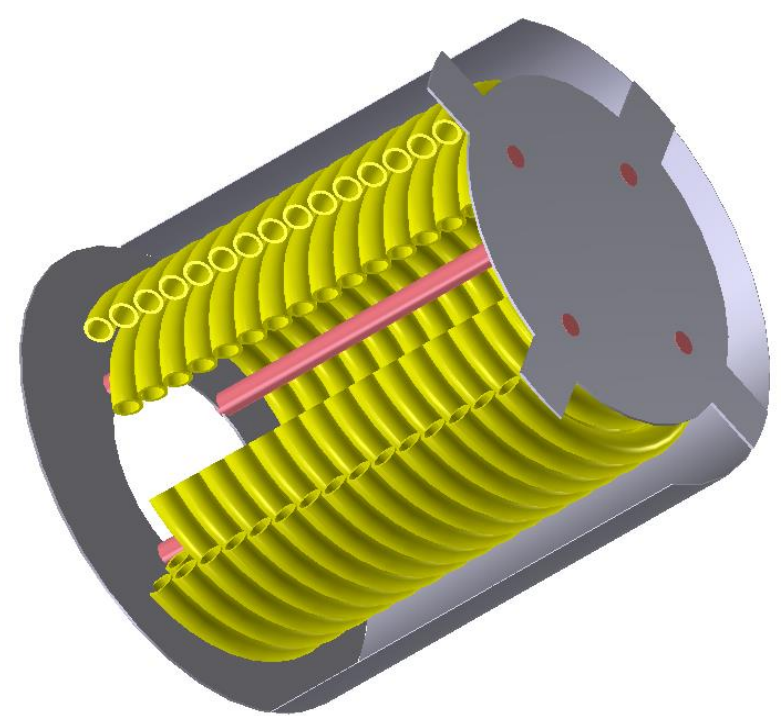

Figure 16: CAD drawing of Nylon HX design
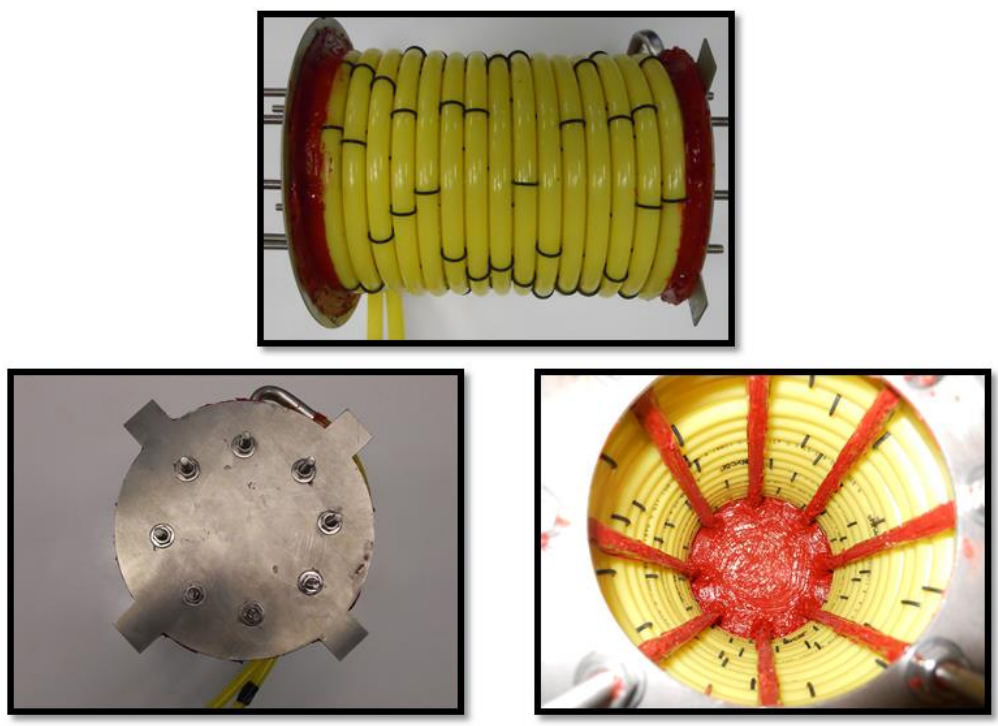

Figure 17: Constructed Nylon HX

Table 2: Dimensions and Specifications of the Polymer Heat Exchanger

\begin{tabular}{|c|c|}
\hline Thermal Conductivity & $0.25 \mathrm{~W} / \mathrm{mK}$ \\
\hline Length & 13.8 meters \\
\hline Tubing I.D. & 0.009 meters \\
\hline Tubing O.D. & 0.012 meters \\
\hline Inner Coil I.D. & $43 / 16 "$ \\
\hline Inner Coil O.D. & $51 / 8^{\prime \prime}$ \\
\hline Outer coil I.D. & $51 / 40 "$ \\
\hline Outer coil O.D & $629 / 200 "$ \\
\hline Revolutions & 15, clockwise \\
\hline
\end{tabular}


Once the design was complete the heat exchanger was installed following the System 2000 Energy Kinetics high efficiency boiler. The installation can be seen in Figure 18 below. The heat exchanger was installed on an angle so if condensing should occur the condensate may be collected from the drain within the duct. The tests conducted used a water bath which was heated to approximately $110^{\circ} \mathrm{F}$ and fed as the inlet water stream, which simulated integration into a home-heating system as the cold water return. Results seen below in Figure 19 are a good representation of data collected from multiple tests.

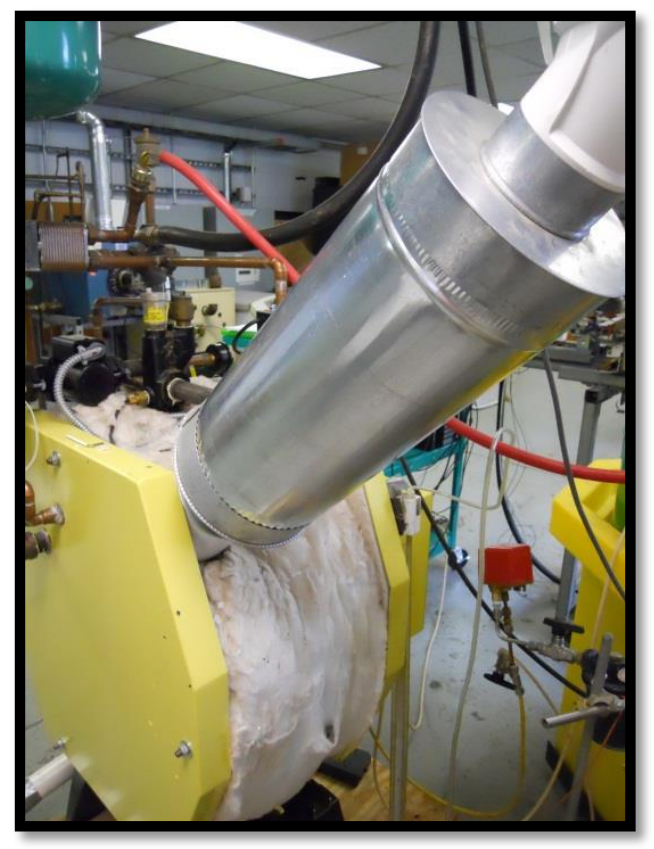

Figure 18: Heat exchanger installation 


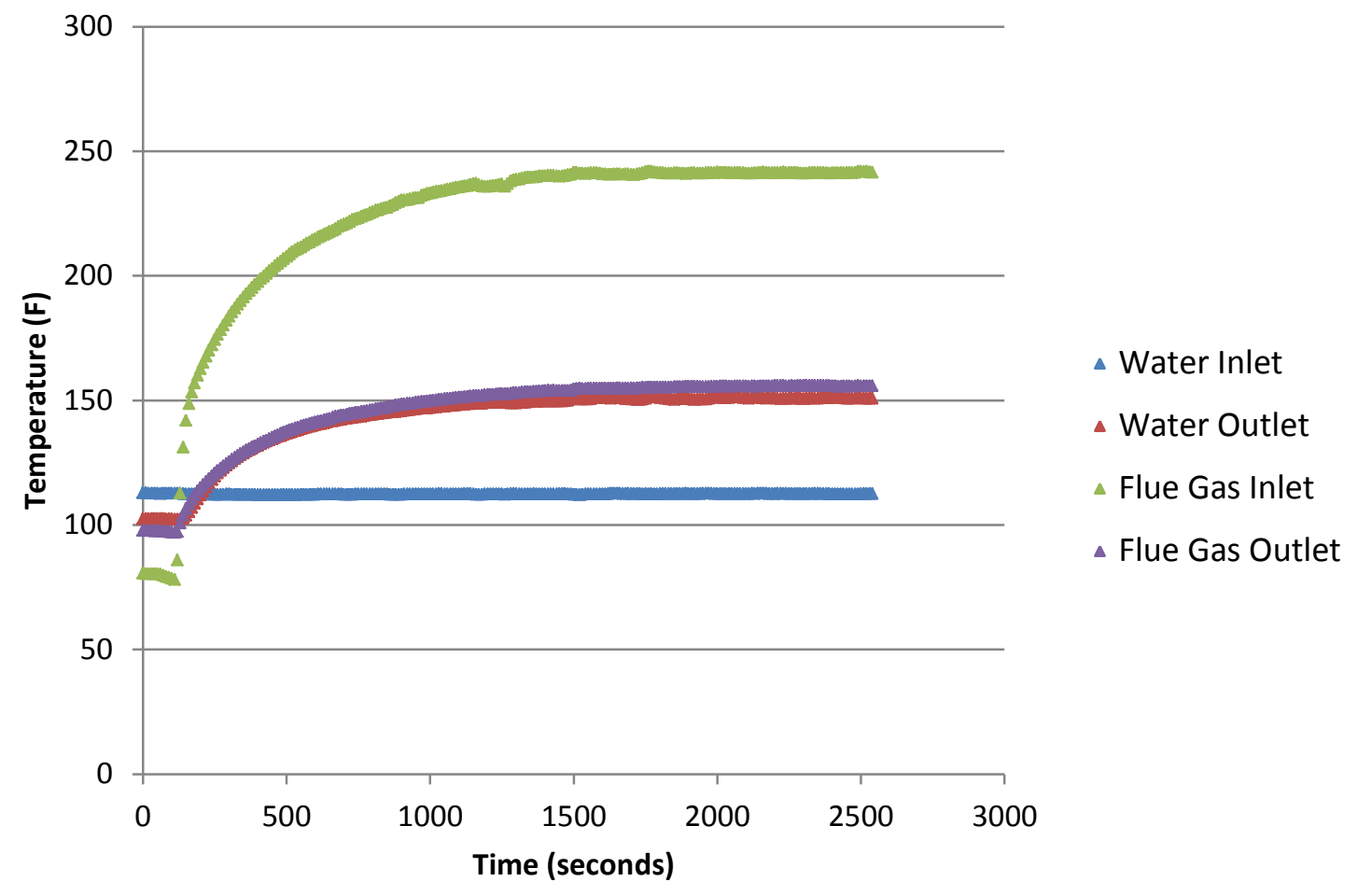

Figure 19 Heat exchanger test - temperatures.

After 24 minutes steady state was achieved and measurements were taken. Boiler and exhaust conditions such as $\mathrm{O}_{2}, \mathrm{CO}, \mathrm{CO}_{2}$ levels were within spec along with a pressure drop of 0.1 across the heat exchanger. A firing rate of $0.74 \mathrm{gal} / \mathrm{hr}$ was maintained, achieving a boiler capacity of 103,512 BTU/hr. From the gas temperature change, a capacity of 2,665 BTU/hr across the plastic heat exchanger was accomplished. With mass flow rate of $0.006 \mathrm{~kg} / \mathrm{s}$ and delta $\mathrm{T}$ of $38.4^{\circ} \mathrm{F}$ on the water side, a total heat transfer rate of $1015 \mathrm{~W}$ was calculated. The total heat transfer coefficient of approximately $21 \mathrm{~W} / \mathrm{m}^{2} \mathrm{~K}$ was also determined.

With no design failure and heat transfer, the preliminary tests indicated the proposed design was effective. Next, a material with a greater thermal conductivity to improve the performance of the heat exchanger was required. Products from the Cool Polymer® Company offered a solution. Discussion with the company offered a few suggestions which would offer the desired thermal conductivity, along with the material properties for process ease. With the exception of the D4302 polymer, both E1201 and RS1486 polymers had polypropylene bases with an unknown filler material to increase the materials thermal conductivity. The D4302 polymer had a copolyester elastomer base, also with filler material to increase the thermal conductivity. The material properties of these three polymer composites in comparison with pure polypropylene may be seen below in Figure 20. 


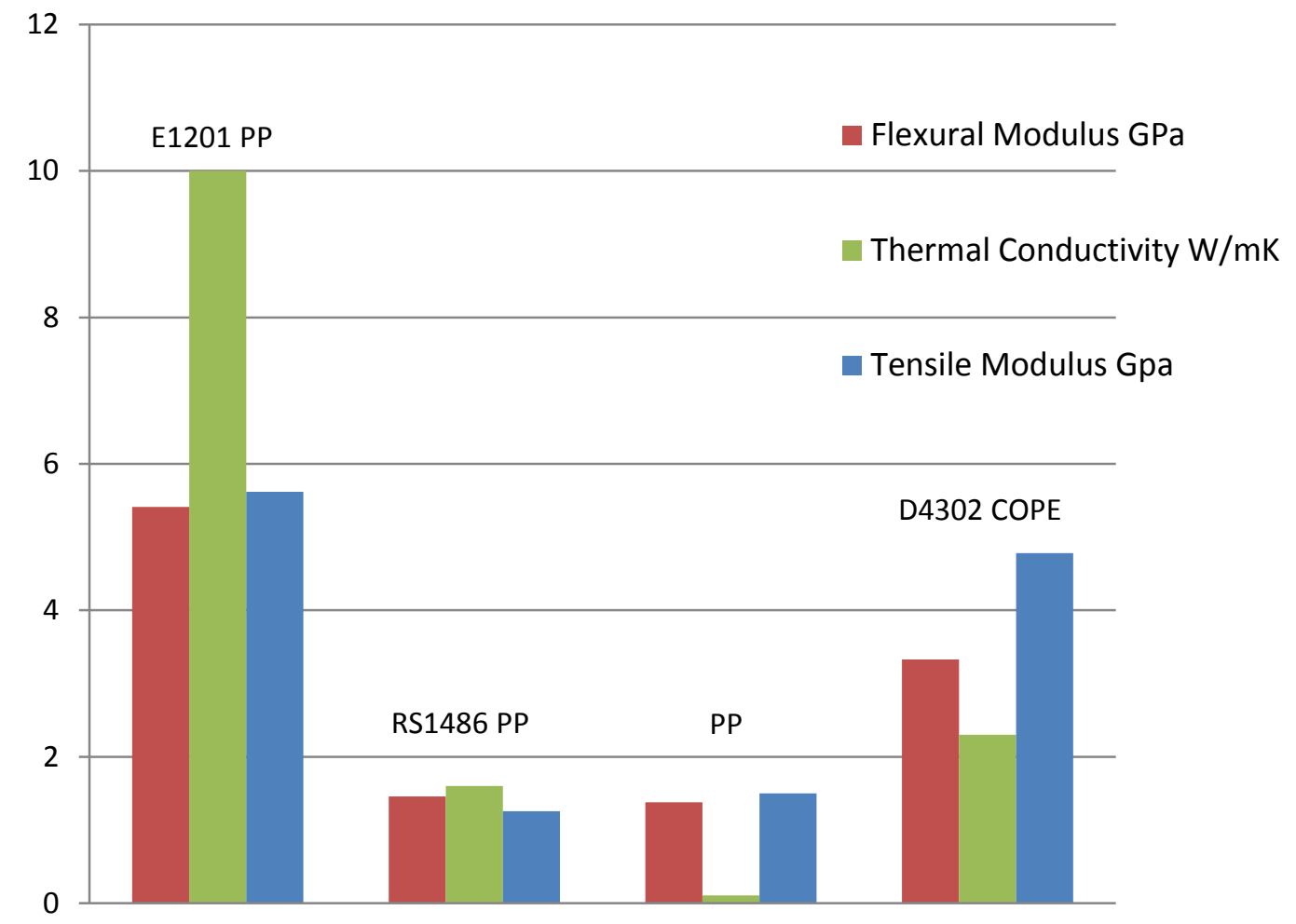

Figure 20: Candidate commercial conductive polymers - property comparison

\section{Extrusion and Processing of Thermally Conductive Polymer Heat Exchanger}

After contacting numerous companies International Polymer Engineering (IPE) in Tempe, Arizona was able to meet the heat exchanger's design request. Concerns about the stiffness of the thermally conductive polypropylene material (RS1486) existed. Due to the materials high loading the difficulty in processing was expected to be tremendous. The additives in the polymer not only enable the temperature transmission but also acted as physical reinforcements.

Almost all extrusion processes pass melt through wire-mesh screens on the way to the die to provide filtering and improved mixing. IPE found the screens caught much of the loading material; therefore screening may not be an option when processing the Cool Polymer® material. After IPE contacted Cool Polymers Inc. a new material D4302 was recommended. Thermally Conductive Copolyester Elastomer D4302 (COPE) from Cool Polymer ${ }^{\circledR}$ had a thermal conductivity of $2.3 \mathrm{~W} / \mathrm{mK}$, better than the $1.6 \mathrm{~W} / \mathrm{mK} \mathrm{RS} 1486$ which was initially considered. The materials properties suggested the tubing was physically more like the Nylon-12; the original exchanger's material but a little bit stiffer. The D4302 COPE material was also more common offering more processing history. Due to tight tolerances, the final product would have to be two coils later fashioned together using a U-bend as in the first prototype exchanger, seen below in Figure 21. The actual coils extruded from IPE with the D4302 material may be seen in Figure 22. 


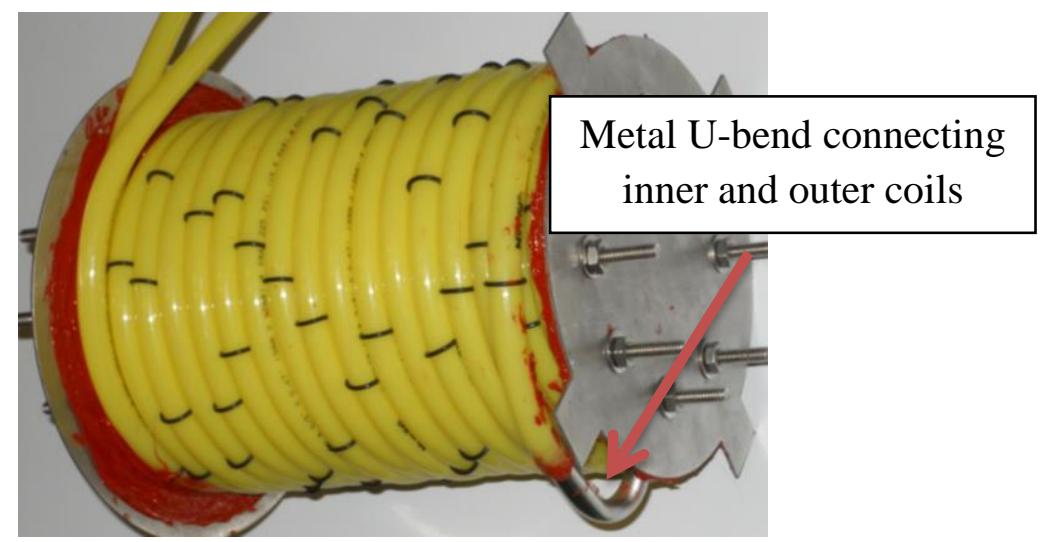

Figure 21: Preliminary design of polymer heat exchanger

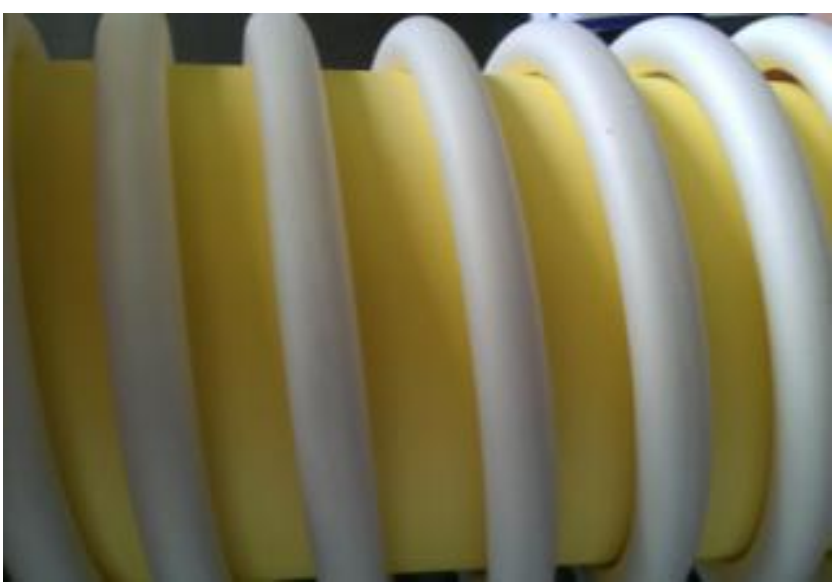

Figure 22: Extruded helical coil of the thermally conductive polymer (coil spacing expanded for photo)

\section{Tests with Thermally Conductive Heat Exchanger}

Testing of the coiled heat exchanger was done with the same boiler as used with the coiled Nylon heat exchanger. Table 3, below provides a summary of the test results at two different excess air levels. Increasing the excess air increases the gas temperature entering the heat exchanger and simply provides data at a different condition. Both tests were done with the boiler operating in steady state.

Table 3 Summary of Boiler Test Results with Thermally Conductive Polymer Heat Exchanger

\begin{tabular}{|l|l|l|l|l|}
\hline Test & Gas in $(\mathrm{F})$ & Gas out $(\mathrm{F})$ & Water in $(\mathrm{F})$ & Water out $(\mathrm{F})$ \\
\hline 1 & 222 & 101 & 102 & 120 \\
\hline 2 & 245 & 133 & 99 & 117 \\
\hline
\end{tabular}


The performance of the heat exchanger with the thermally conductive polymers was considerably better than that of the Nylon coil.

\section{Coupon Tests for Material Analysis}

An examination of the corrosion a material is subject to in its exposed environment is critical in terms of maintenance, repair costs, and material failure. Coupon testing provides an inexpensive and preliminary study to effectively measure the corrosivity within the system and its effects on the material of construction. By analyzing the corrosion of the exposed coupon, valuable information can be gained regarding the material's performance and life expectancy.

Literature suggests polypropylene is inert to acidic flue gases, however there is the potential the filler material may be affected leading to leakage paths and failure. Even if the polymer itself is not affected, the acids in the condensate have the potential to attack the filler material, leading to leakage paths and failure. To understand the potential degradation in the actual condensing environment of thermally conductive polymers, tests at BNL were performed using the CoolPoly® E1201 thermally conductive polypropylene (PP). To compare the resistance of the thermally conductive polymer to other common heat exchanger materials, three other coupons were also tested; cast aluminum, aluminized steel (ALSI), and a steel boiler sample obtained from Energy Kinetics, Inc (EK)

Table 4 Coupon Tests - Summary of Conditions

\begin{tabular}{|c|c|c|}
\hline \multicolumn{3}{|c|}{ Conditions } \\
\hline Coupons & & \\
\hline \multirow{11}{*}{$\begin{array}{l}\text { E1201; Cast } \\
\text { Aluminum; } \\
\text { ALSI; EK }\end{array}$} & $\mathrm{O}_{2}$ & $7.2 \%$ \\
\hline & $\mathrm{CO}_{2}$ & $10.2 \%$ \\
\hline & $\mathrm{CO}$ & $2 \mathrm{ppm}$ \\
\hline & $\mathrm{NO}_{\mathrm{X}}$ & $65.3 \mathrm{ppm}$ \\
\hline & $\mathrm{SO}_{2}$ & $0 \mathrm{ppm}$ \\
\hline & Efficiency & $84.3 \%$ \\
\hline & Smoke No. & 0 \\
\hline & $\begin{array}{c}\text { Start-up } \\
\text { Smoke No. }\end{array}$ & $2+$ \\
\hline & Stack Temp & $435^{\circ} \mathrm{F}$ \\
\hline & Cycle Time & $\begin{array}{c}3 \text { min on, } 4.5 \text { min } \\
\text { off; } 8.6 \text { hrs on, } 14.4 \\
\text { hrs off }\end{array}$ \\
\hline & Fuel use & $4.8 \mathrm{gal} / \mathrm{day}$ \\
\hline
\end{tabular}

A thermocouple was placed in the center of the CoolPolymer sample which was the first coupon exposed to the hot flue gas in box two and read a temperature of $115^{\circ} \mathrm{F}$. The temperatures for the 
PVC surface, coupon box one and coupon box two read $125^{\circ} \mathrm{F}, 108^{\circ} \mathrm{F}$ and $108^{\circ} \mathrm{F}$, respectively. Figure 23 below shows the layout of each coupon box. Initial surface condition was known, initial weight and dimensions were not. Location, condition and time of exposure were also known.

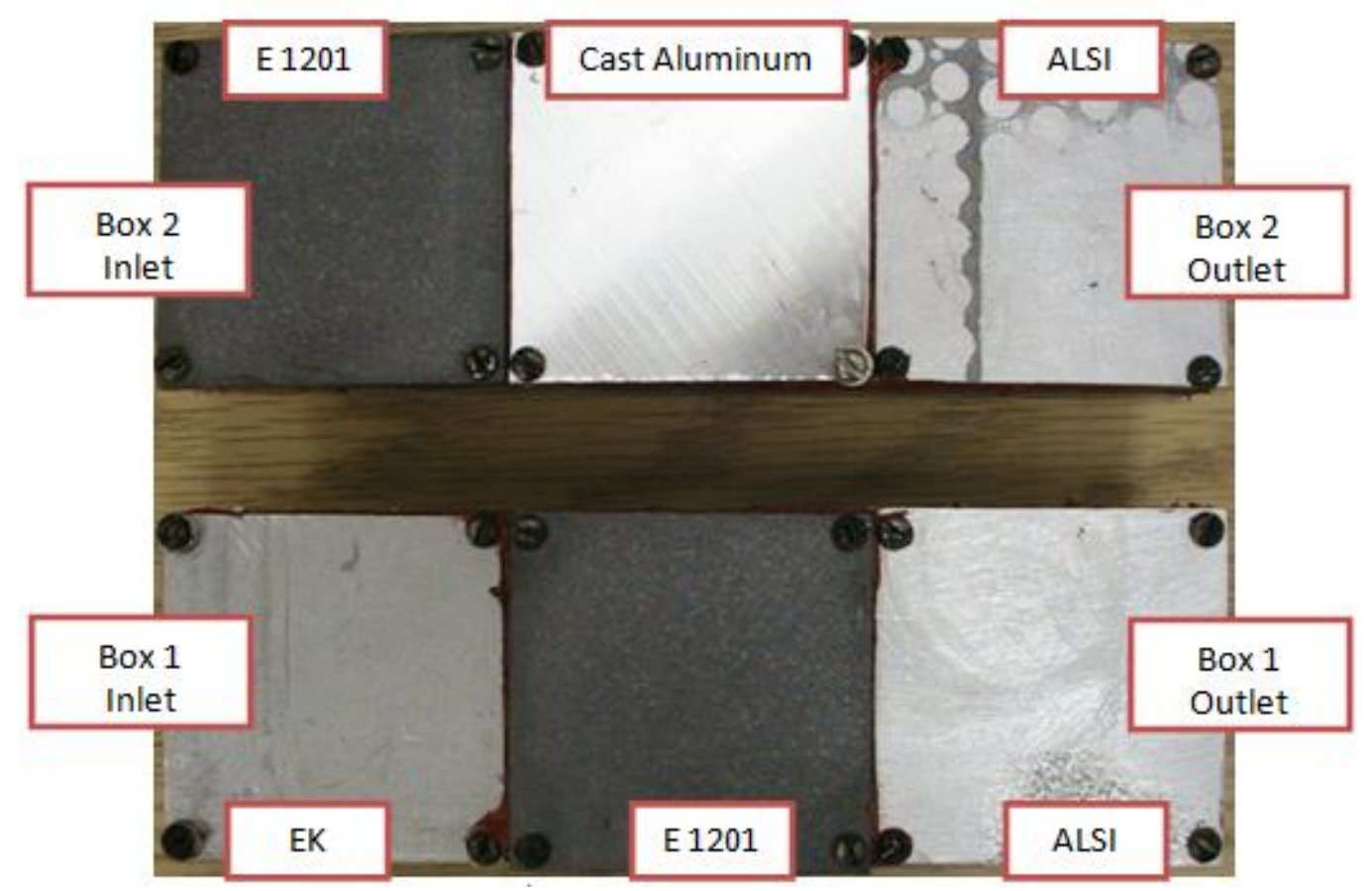

Figure 23: Coupon layout

After 63 days of cyclic testing (504 hours), the coupon experiment was complete and the polymers degradation could be analyzed. Figure 24 below shows the coupons after testing was complete and flue gas deposit. Typically, degradation analysis may be done using the Princeton Applied Research analysis tool set including Flat Cell, Computer Interfaced Potentiostat and corrosion analysis software suite, which provides a Taefel plot. Unfortunately this instrument is not fully applicable for polymers and the results would only produce guidelines. 


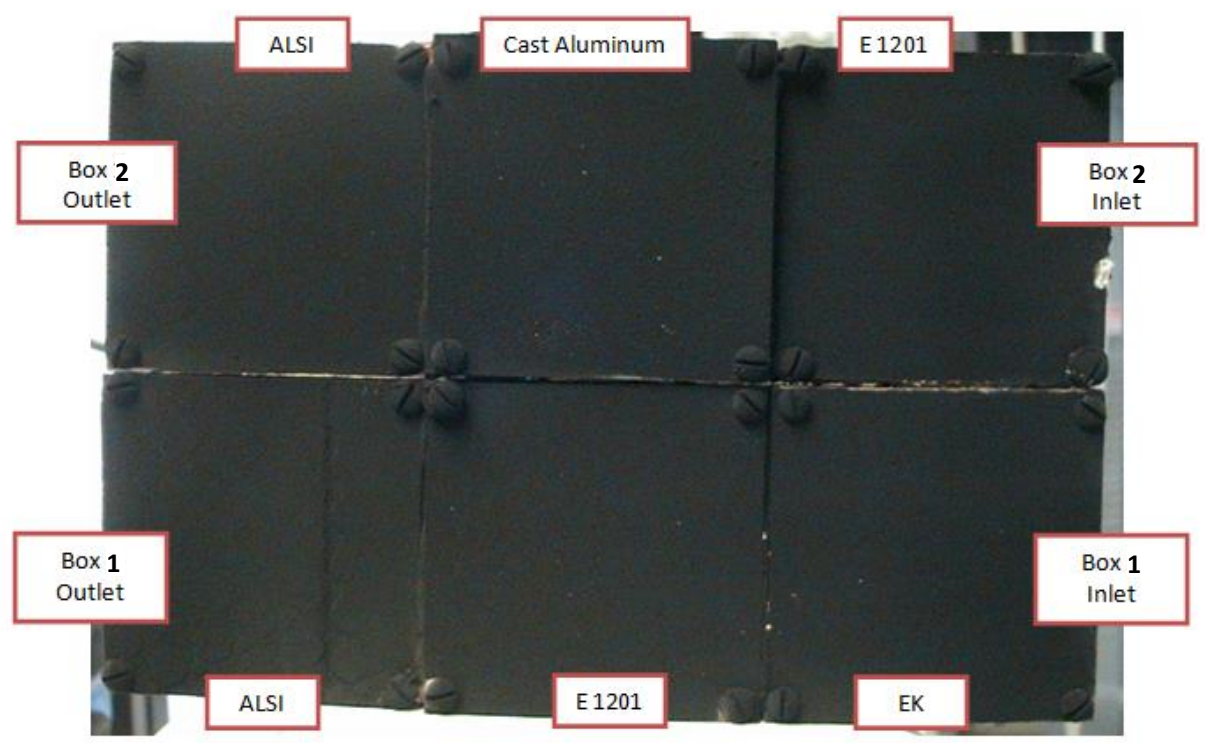

Figure 24: Coupons after 63 days

As an alternative approach, an elemental and topographical analysis was conducted on the polymer sample. With a Scanning Electron Microscope (SEM) information of the polymer's surface at the microscopic scale was gained. As an electron beam struck the examined surface, the electrons interacted with the material's atoms, producing signals that contained information about the surfaces topography and ultimately provided an image of the materials surface. Further, Energy-dispersive x-ray spectroscopy (EDX) was used to understand the elemental composition of the material. The sample was again struck with a high-energy beam of electrons, causing the specimen atoms' own electrons to become excited and emit x-rays and energies which were then measured. Because different energy levels are associated with different elements, the different elements present within the sample were known.

Initially, a control coupon which had not been exposed to any flue gases was analyzed using the SEM and EDX. This provided general idea of the polymer's composition and confirmed the literature's description of its composition- specifically patent number 7655719, Thermally conductive polymer compositions having moderate tensile and flexural properties, issued to Cool Options, Inc. with James D. Miller as the inventor. Fillers of the thermally conductive polymer included suitable non-metallic and metal oxides such as alumina, magnesium oxide, zinc oxide and titanium oxide; ceramics such as silicon nitride, aluminum nitride, boron nitride, boron carbide and carbon materials such as black or graphite. Metallic fillers such as aluminum, copper and stainless steel were also used. It was specified the thermally conductive fillers comprised about 20 to $80 \%$ by weight of the total compositions. These additives were in the form of particles, powder, whiskers, fibers, etc. Flame retardants may also have been mixed in. 
As seen in Figure 25 the E1201 contained many non-uniform structures, however much of the structure appeared to consist of graphite flakes. This was consistent with the patent's literature where a co-polymer base matrix of thermoplastic elastomers and stiffer thermoplastic resins is used along with 20 to $80 \%$ by weight of thermally-conductive fillers.

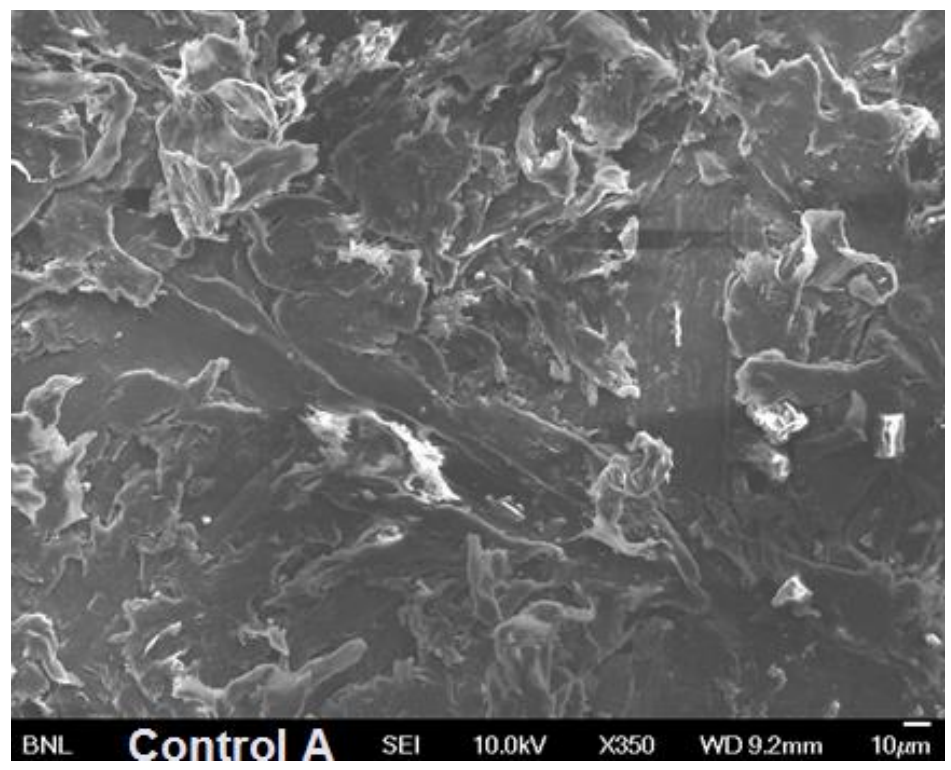

Figure 25: SEM image of unexposed coupon

Figure 26 a zoomed in portion of the sample again shows one of the diverse structures constructing the polymer. It is important to note, the "glowing" white parts of the sample may be non-conductive materials or tall pieces of the sample, in both cases the electrons which are beamed at the sample are unable to reach the ground. 


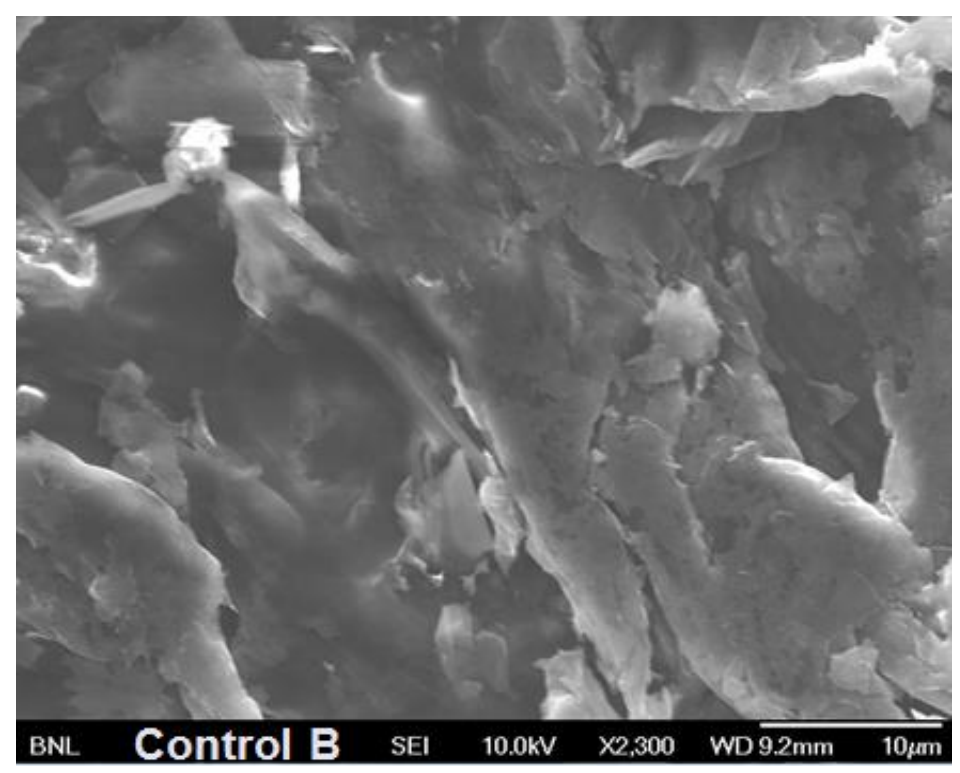

Figure 26: Closer SEM image of unexposed coupon

Performing a qualitative elemental analysis illustrated the majority of the thermally conductive polymer was carbon $(\mathrm{C})$, but the material also consisted of aluminum (Al), iron $(\mathrm{Fe})$, potassium $(\mathrm{K})$, magnesium $(\mathrm{Mg})$, sodium $(\mathrm{Na})$, oxygen $(\mathrm{O})$, and silicon $(\mathrm{Si})$. Performing a quantitative analysis quantified the weight percent of each element found in the sample in addition to confirming the peaks that may have been speculative. False or artifact peaks are typical of any $\mathrm{x}$ ray software. These artifacts are expected due to limitations in the software, overlaps, sum peaks, escape peaks, and/or impurities in the x-ray source itself. To determine false positives or false negatives the spectra is evaluated carefully for positive identification of an element such as the observation of two peaks at energies close to their tabulated values. These results may be seen in Figures 27 through 29. 


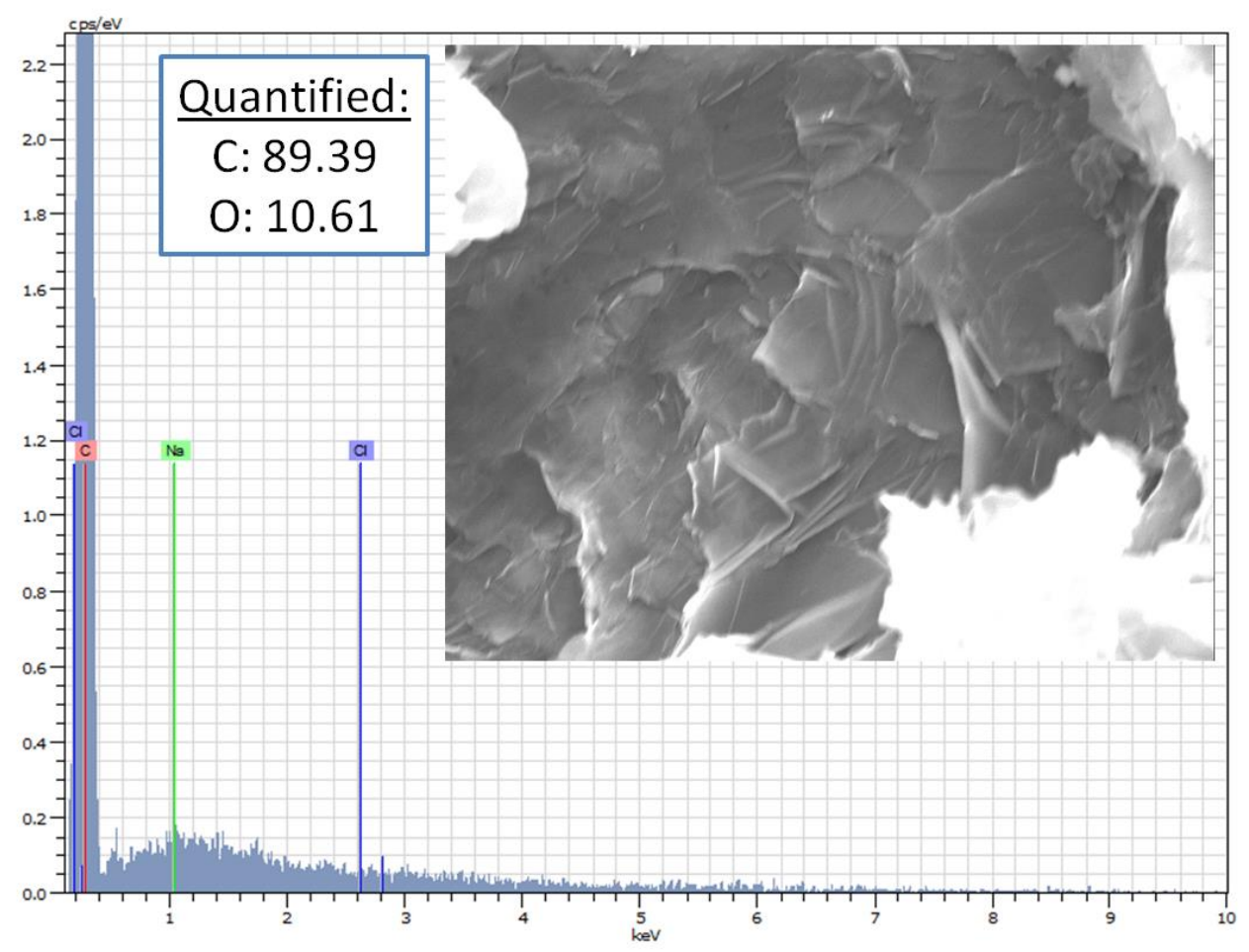

Control 2 Date:3/21/2012 2:17:33 PM HV:20.0kV Puls th.:2.14kcps

Figure 27: EDX of unexposed coupon (1)

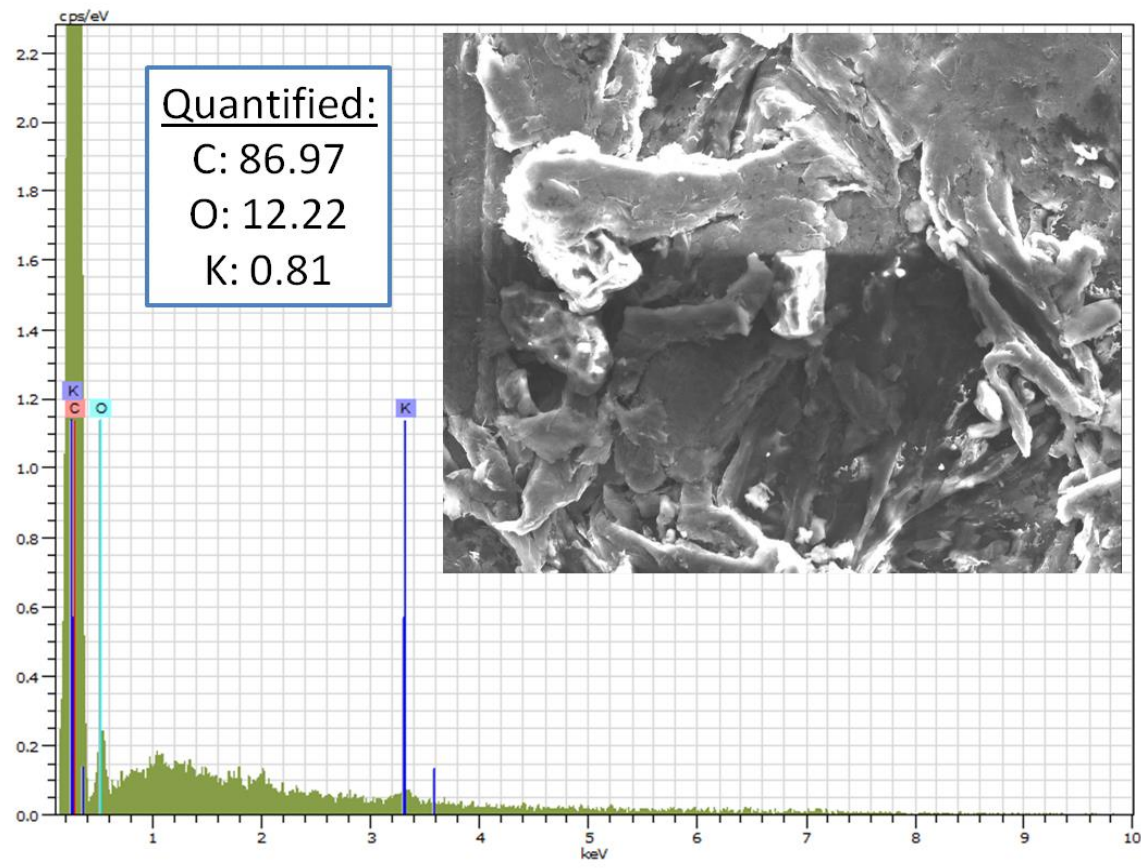

Control 3 Date:3/21/2012 2:25:01 PM HV:20.0kV Puls th.:2.19kcps

Figure 28: EDX of unexposed coupon (2) 


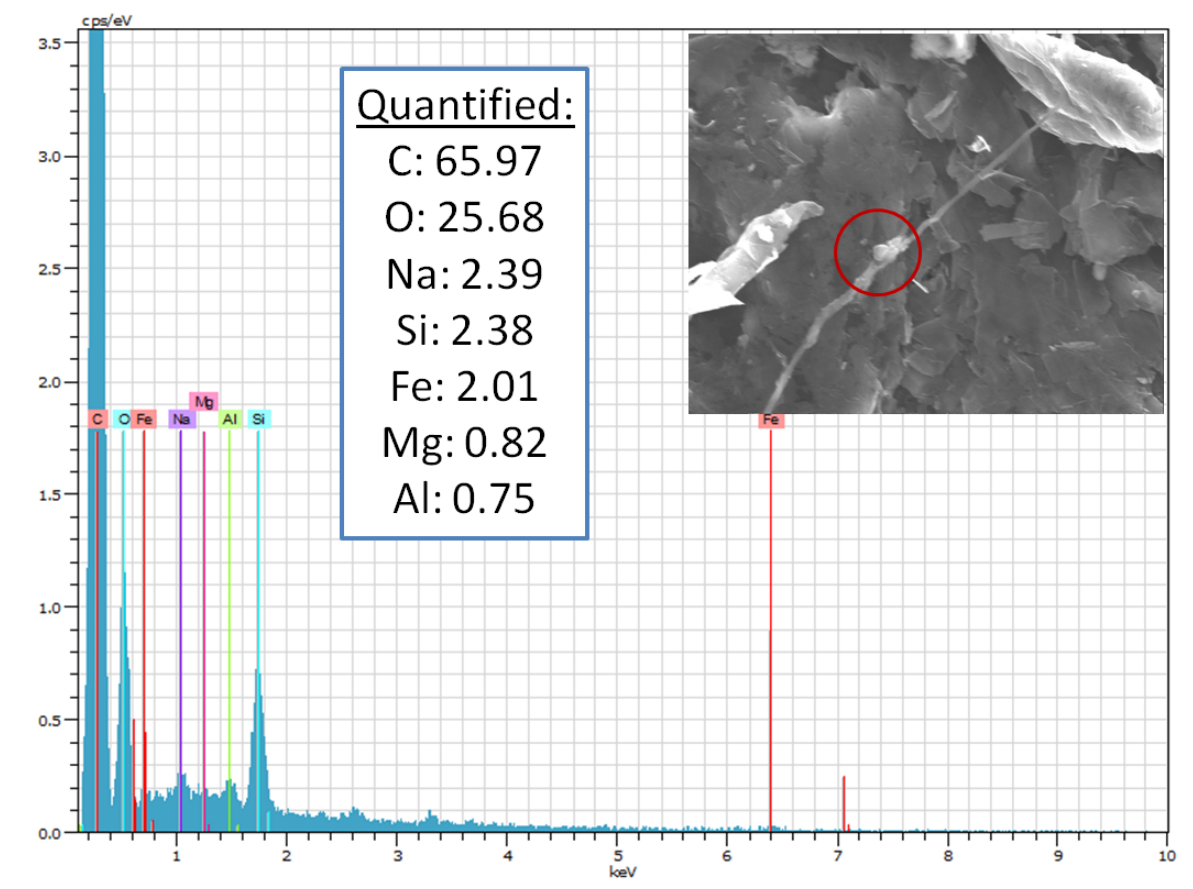

Control 4 Date:3/21/2012 2:57:41 PM HV:20.0kV Puls th.:2.64kcps

Figure 29: EDX of unexposed coupon (3)

Before analyzing the exposed coupon the surface was wiped to remove the thick coat of carbon deposit which was seen above in Figure 24. When studying the exposed coupon at a macroscopic scale, the build-up of the combustion products seen on sections of the coupon was uneven. Some sections had deposits while other parts remained "clean", similar to the unexposed coupon. Channeling of the flow of condensate is the expected cause of this observation. At a microscopic level from the SEM it was obvious a rough coating had formed on top of the polymer in some sections.

To properly examine the polymer and its resistance to the acidic flue gas, the focus was on areas which reflected the coupons original surface; focusing less on the buildup of combustion products on the surface. This would determine whether or not the polymer degraded, if the surface topography had altered and how. As seen in Figures 30 through 33 the focus lay on very similar structures to that of the control, such as the graphite flakes. Note the y-axis scale change; while the intensity of the peaks may seem smaller or larger, the quantitative analysis provides a comparative measure between all energy dispersive x-ray spectroscopy (EDX) runs. 


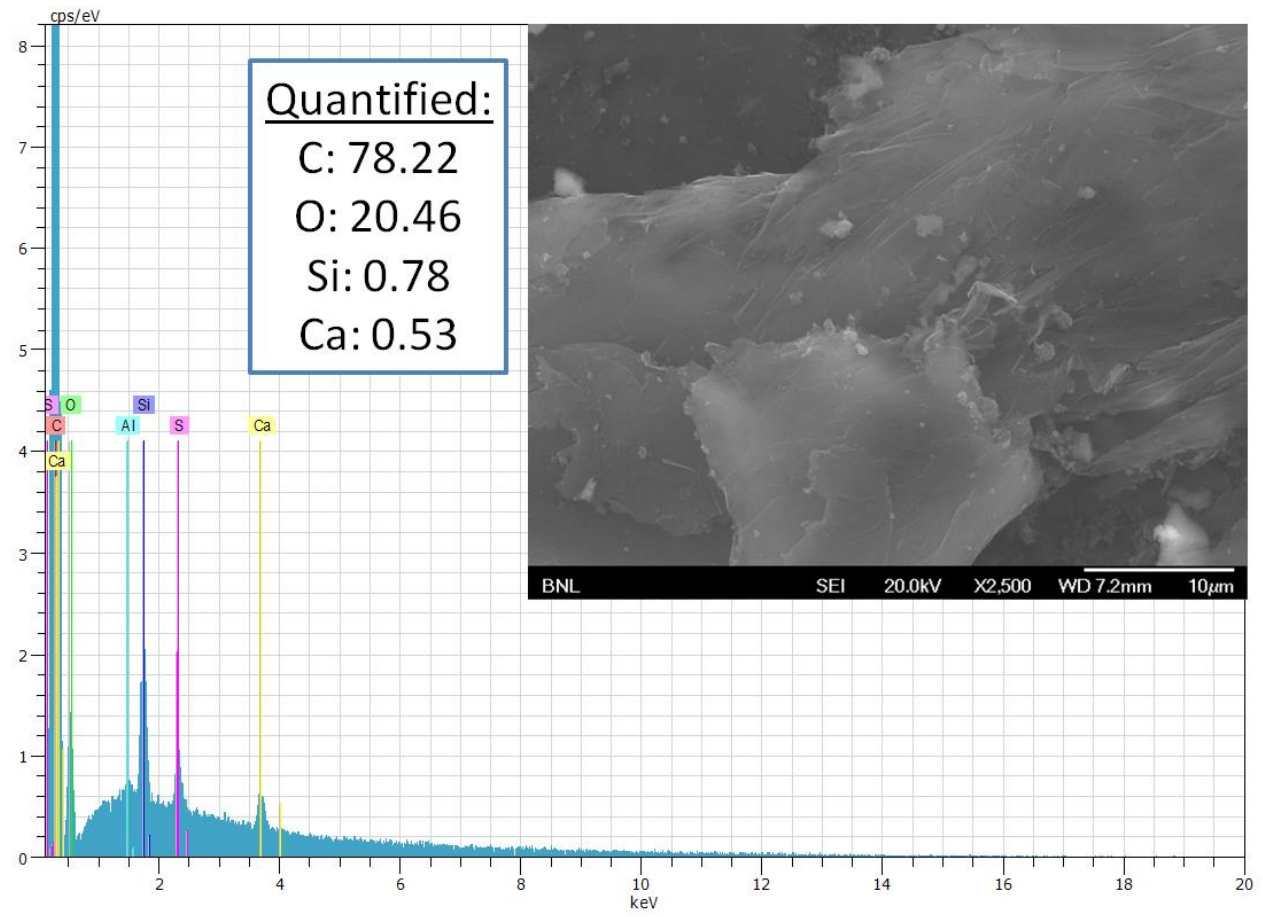

Figure 30: SEM image and EDX results of exposed coupon (1)

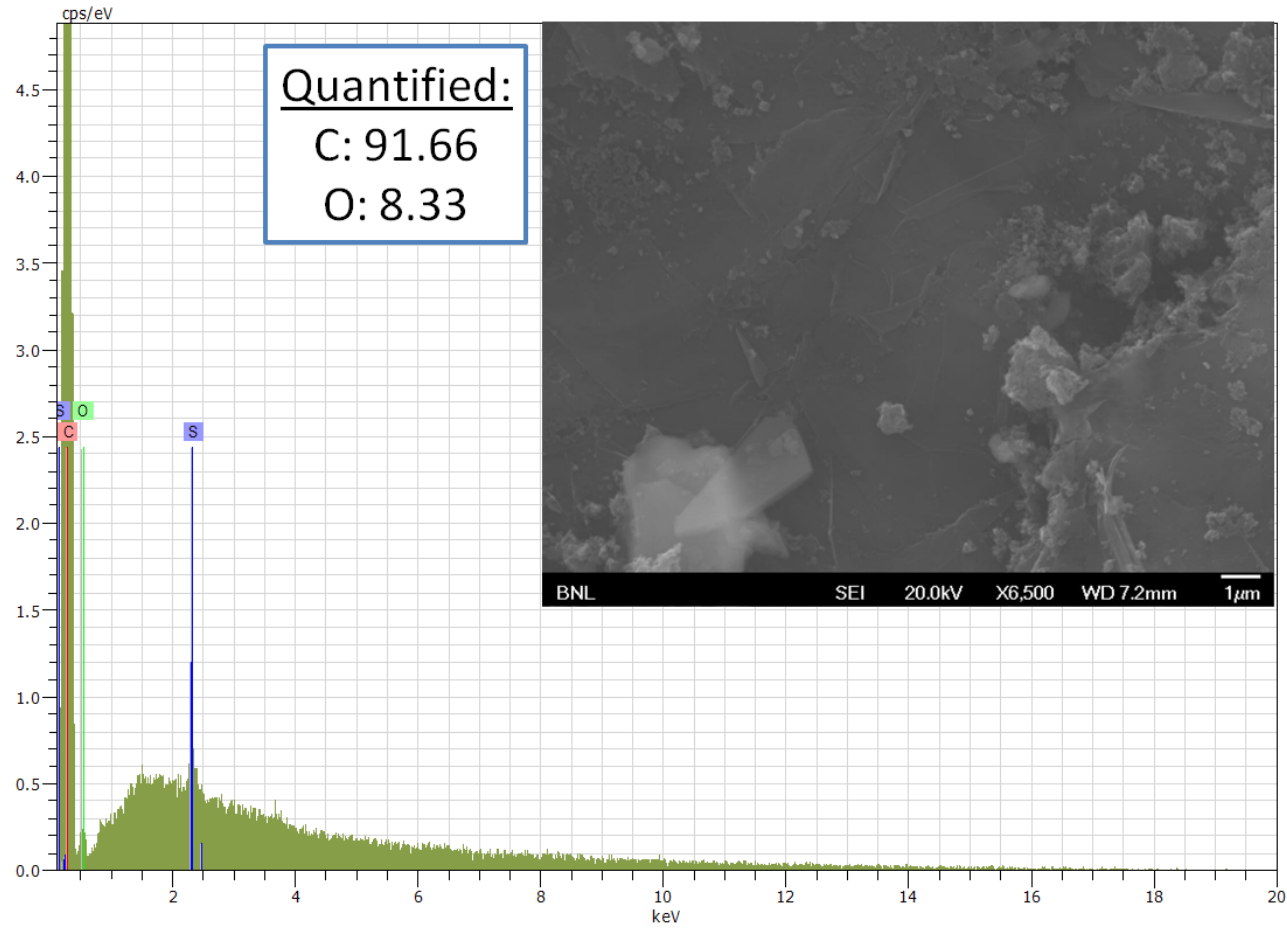

Figure 31: SEM image and EDX results of exposed coupon (2) 


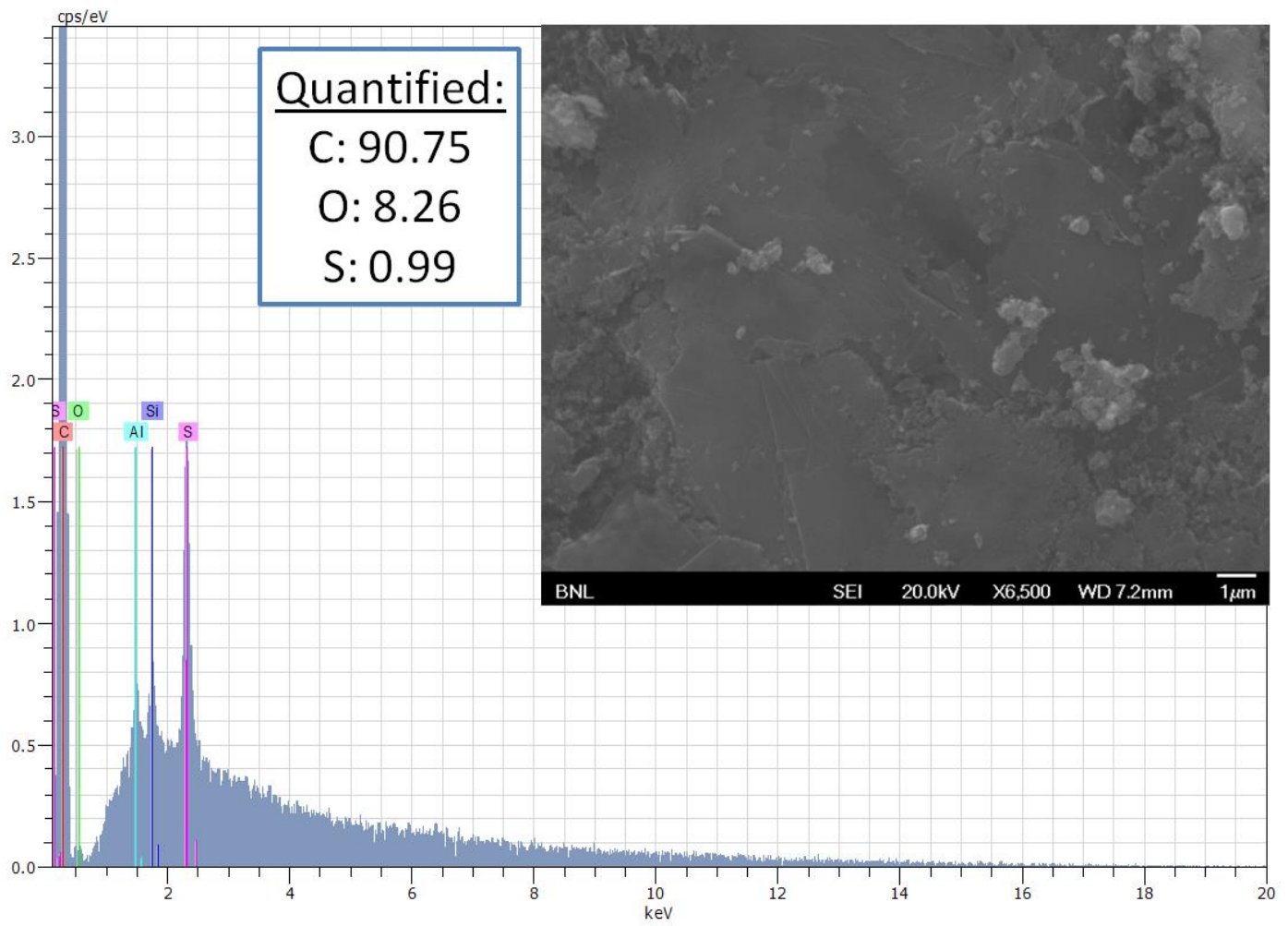

Figure 32: SEM image and EDX results of exposed coupon (3) 


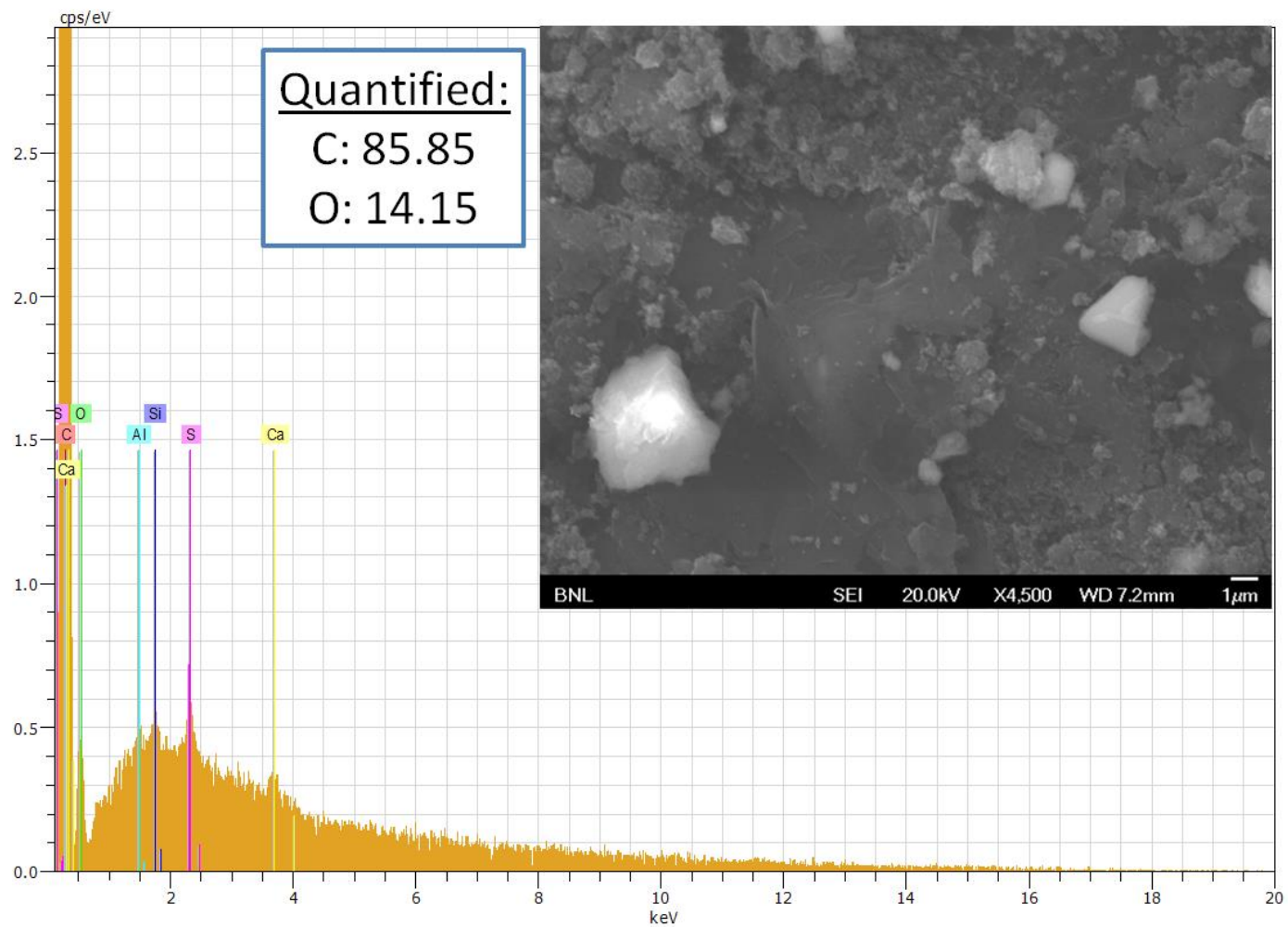

Figure 33: SEM image and EDX results of exposed coupon (4)

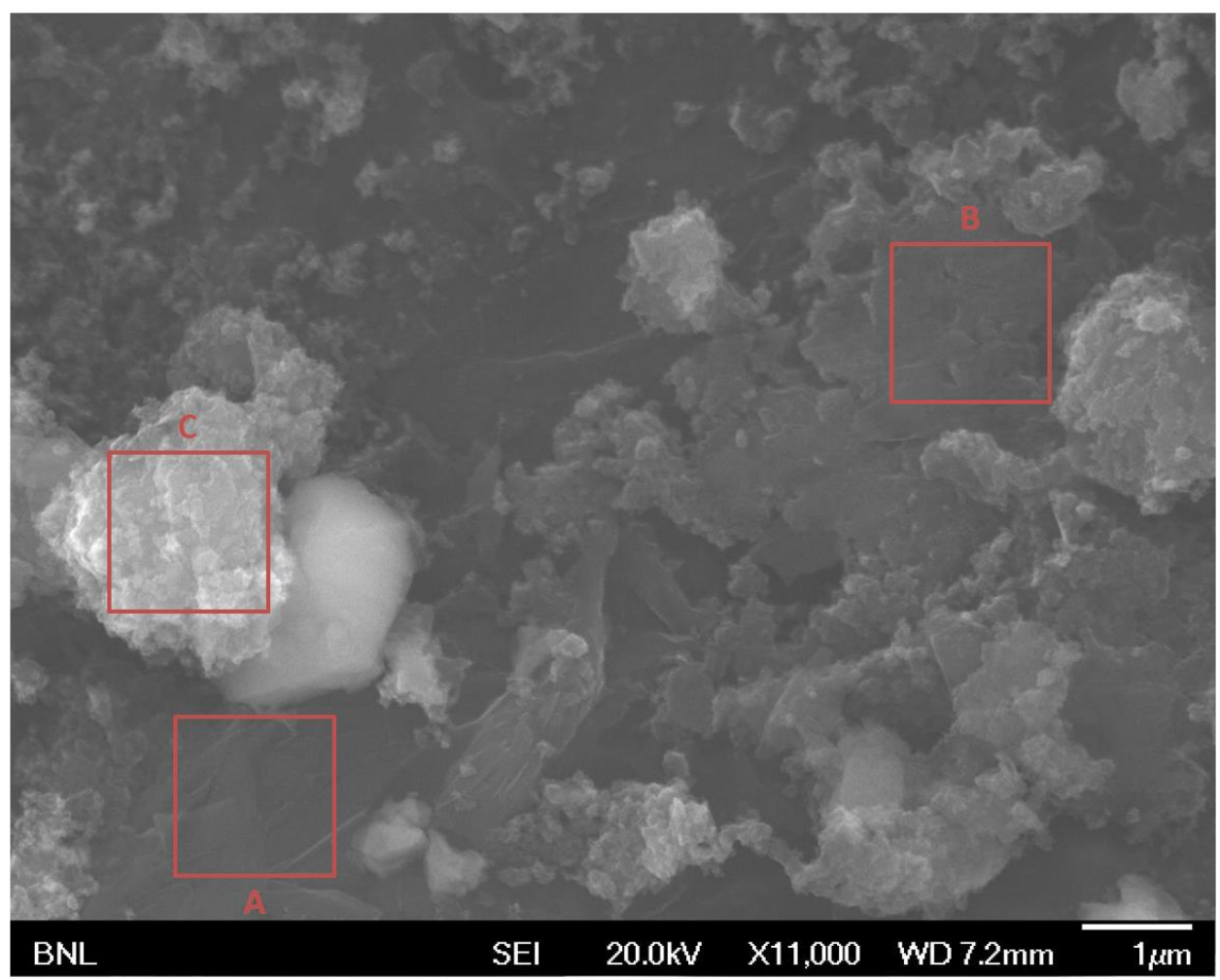

Figure 34: Overall SEM image of exposed coupon 
The EDX analysis seen in Figures 35 through 37 relate to Figure 34.

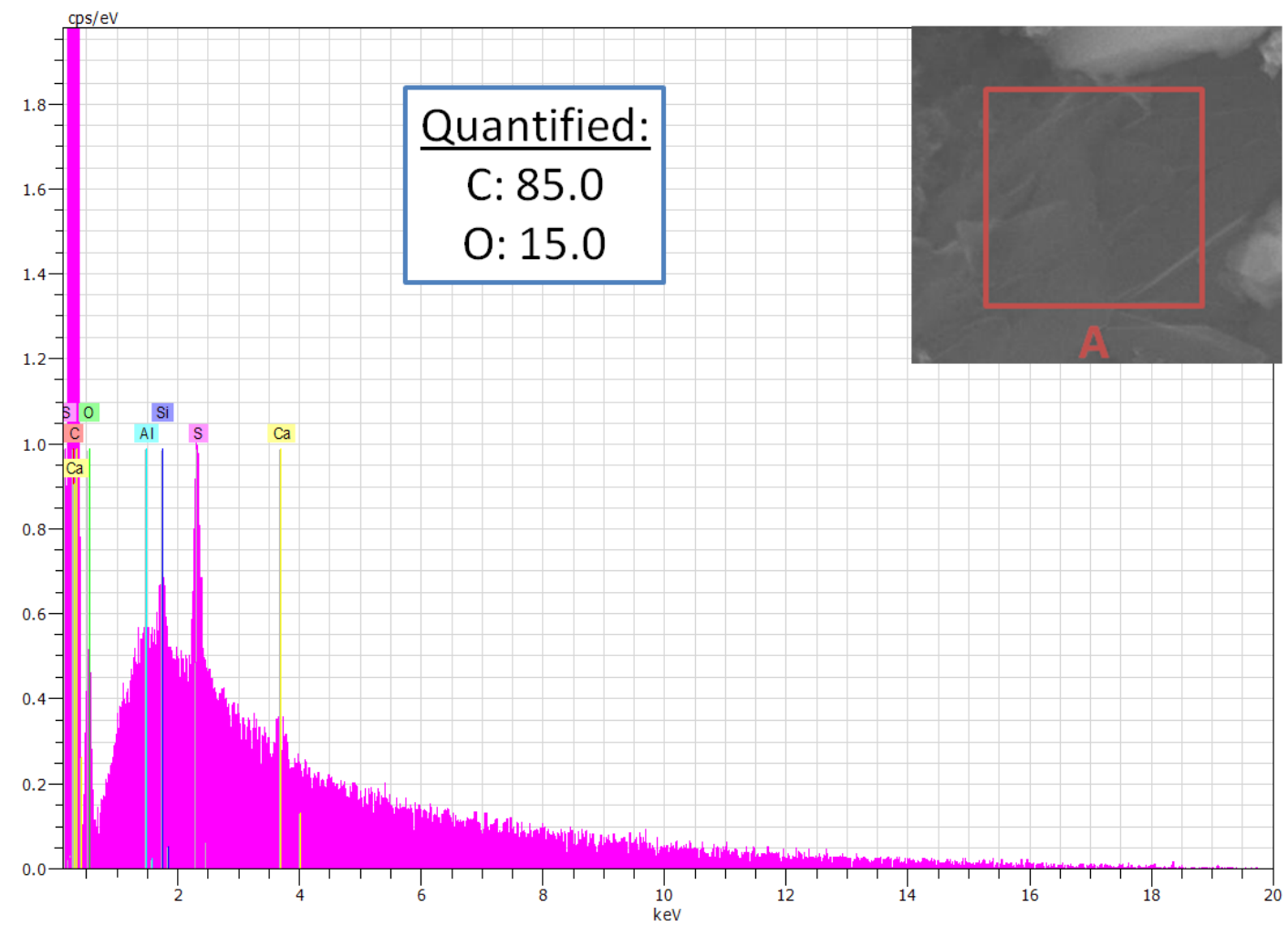

Figure 35: SEM image and EDX results of exposed coupon, section A 


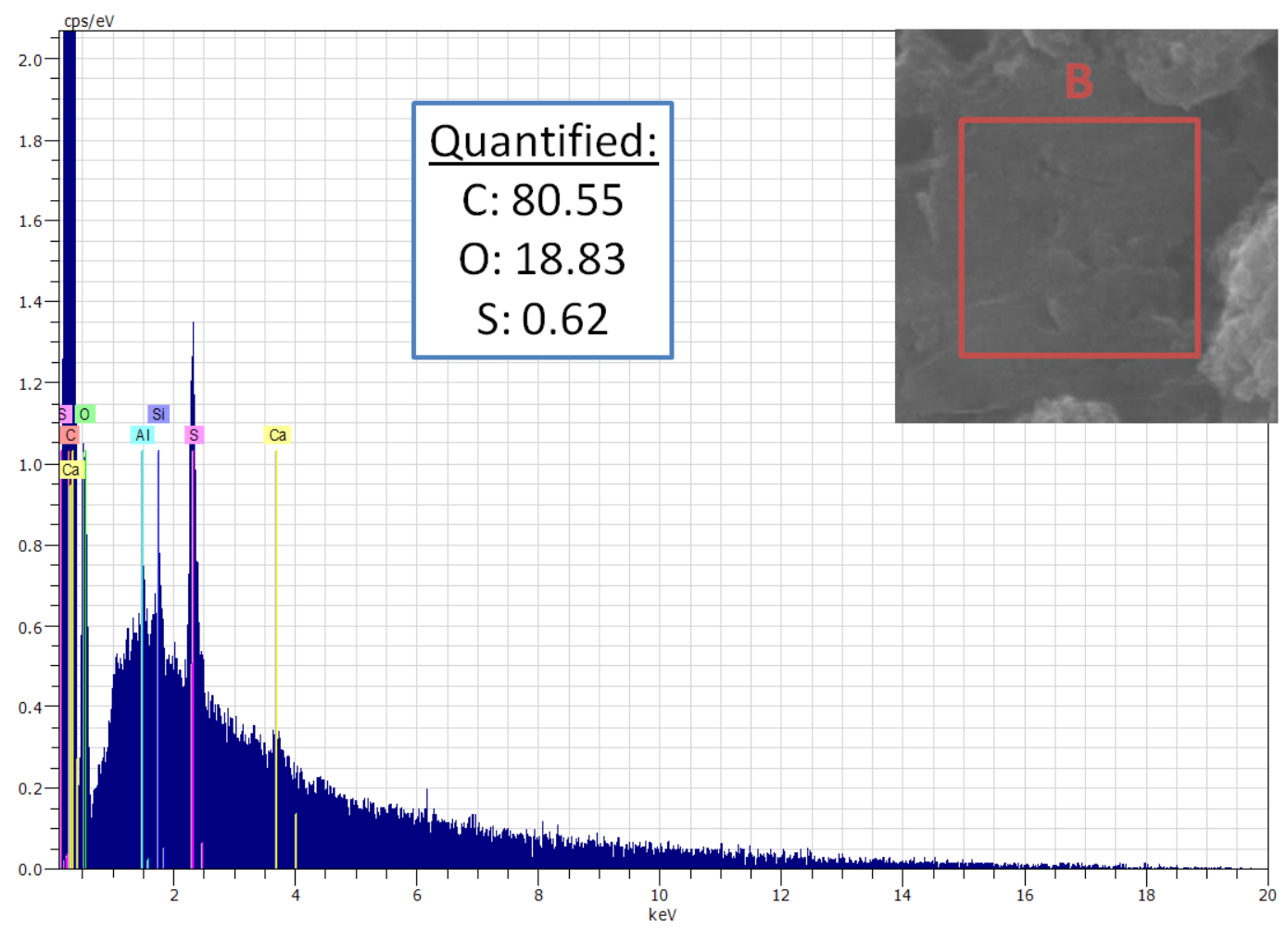

Figure 36: SEM image and EDX results of exposed coupon, section B

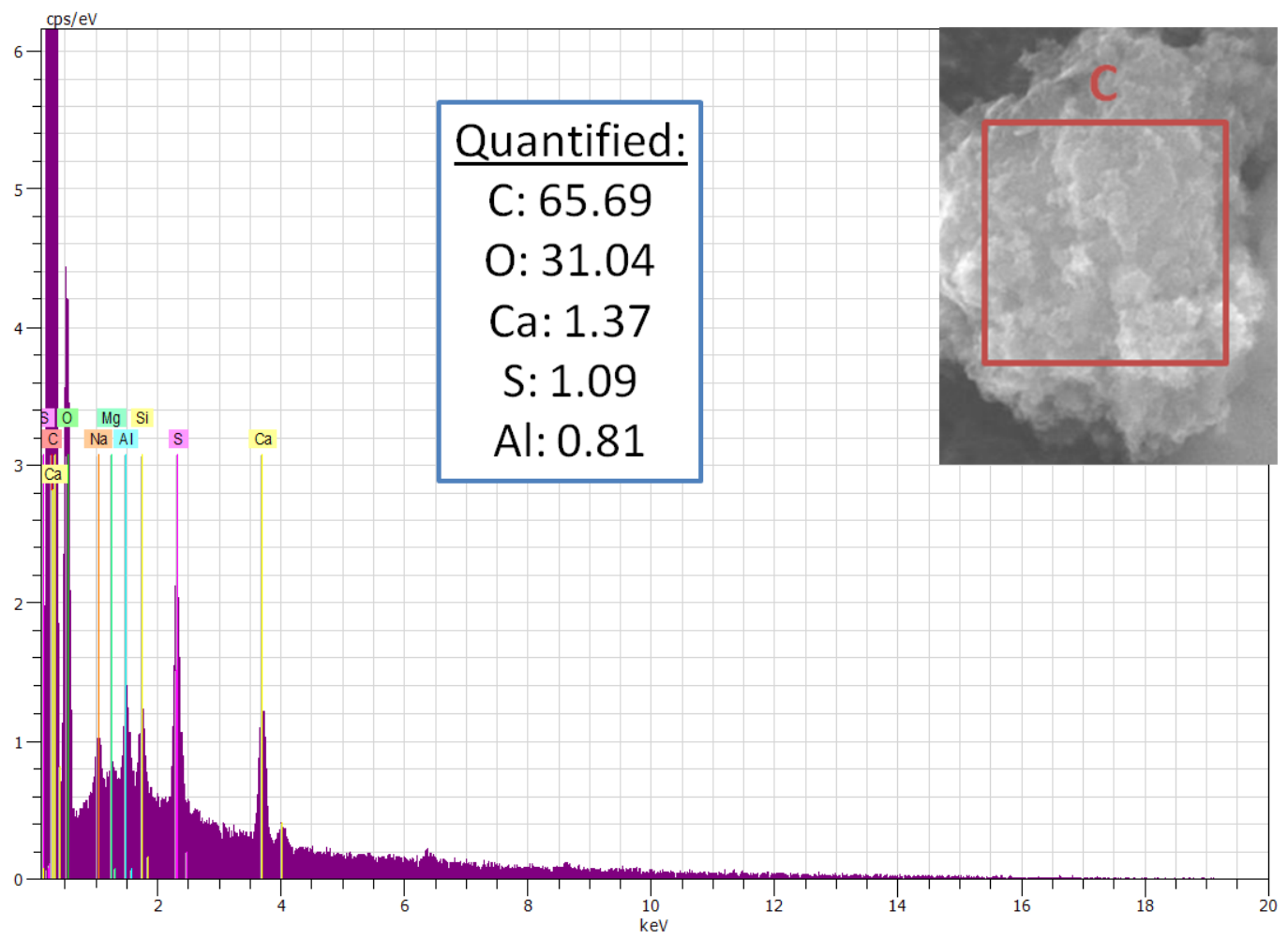

Figure 37: SEM image and EDX results of exposed coupon, section C 
The EDX results of the exposed coupon contained aluminum, calcium, carbon, oxygen, silicon, sodium and sulfur. A closer look at the coupon confirmed our previous conclusion that it is hard to suggest the polymer is actually degrading, but yet the products from combustion are simply depositing on the material. While examining sections similar to the control coupon, EDX results provided fewer elements including carbon, oxygen and sulfur. Performing the quantitative analysis showed oxygen levels do not differ much from the control coupon as well.

When studying areas where much of the deposit is found such as in Figure 37, EDX results contain additional elements such as aluminum, calcium, silicon and sodium. It is also important to note oxygen and sulfur levels are higher when studying the build-up vs. sections which resemble the unexposed polymer coupon; this is typical due to the combustion products. The other elements present on the exposed coupon are the residue make-up found after combustion, referred to as ash. The ash is a mixture of the organic and inorganic substances which are noncombustible.

While ash is seldom found in distillate oils, when present, the cause is generally due to the refining process, with lesser amounts resulting from handling and contamination during the refining process. Ash constituents are separated into five classes; oil-soluble, water-soluble, corrosion products, caustic and lime, and foreign contaminants such as tank rust or dirt. Most prominent (in this study) are the oil-soluble, water-soluble, and the caustic and lime classes:

- Oil-soluble, organic-metallic chemical compounds present in the crude oil are produced during the refining process. The organic portion of the compound is able to burn during the combustion process while the metallic portion deposits as an ash.

- Water-soluble, most often found as salt (sodium and calcium chloride) are present in the water portion of the fuel. During the combustion process the calcium and sodium form oxides and ash.

- Caustic and lime are used to neutralize acids but form inorganic salts which are noncombustible and create ash.

Therefore it is not uncommon to see the variety of elements as seen in the EDX of the ash deposit on the exposed coupon such as aluminum, calcium, magnesium, sodium and silicon. These elements are almost always present in amounts ranging from 0.015 to $0.05 \%$ of the ash ${ }^{5}$. To help deal with the problems associated with ash, standards have been published for the specific fuel grades and limits on the amount of ash permissible.

\footnotetext{
${ }^{5}$ Schmidt, Paul F. "Chapter 10: Ash and Salt Residue." Fuel Oil Manual. New York, NY: Industrial, 1985. 92-97. Print.
} 


\section{Alternative Approach: Evaluation of Polymer-Covered Copper Tubing}

During this project some consideration was also given to a polymer-covered copper tube. The concept is the metal tubing would allow for the desired heat transfer and performance with the addition of corrosion resistance from the outer polymer shell. The material of choice was copper tubing with a seamless inert polyethylene coating. This material is commercially available and has a temperature range of $-94^{\circ}$ to $+219^{\circ} \mathrm{F}$.

To determine whether or not it be worthwhile to assemble the heat exchanger, calculations were carried out in order to understand the performance of the material. The overall heat transfer coefficient (U) is the measure of the overall ability of a series of conductive and convective barriers to transfer heat. The overall heat transfer coefficient considers the individual heat transfer coefficients of each stream and the resistance of the pipe material. Using Equation 1 below, $\mathrm{U}$ is determined through the reciprocal of the sum of a series of thermal resistances. The thermal resistances of the pipe walls are dependent upon the wall's thickness, the materials thermal conductivity and the area of the heat exchanger, as seen in Equation 2. The overall heat transfer coefficient may then be used to solve for the total heat transfer between the two fluid streams using Equation 3:

$$
\begin{gathered}
\frac{1}{U A}=\sum \frac{1}{h A}+\sum R \\
R=\frac{x}{k A} \\
Q=U A \Delta T_{L M}
\end{gathered}
$$

Calculations were based on the same dual helical coil design as discussed above. However; the polyethylene covered copper tubing had different tubing dimensions due to its dual tube design, as seen in Figure 38 and 39. To compare the performance of our first model constructed of Nylon-12 and our current heat exchanger being extruded in Arizona made of the Cool Polymer® thermally conductive polypropylene RS1486, the calculations were completed for these as well. A complete table of tubing specifications for each material may be seen in Table 5. 


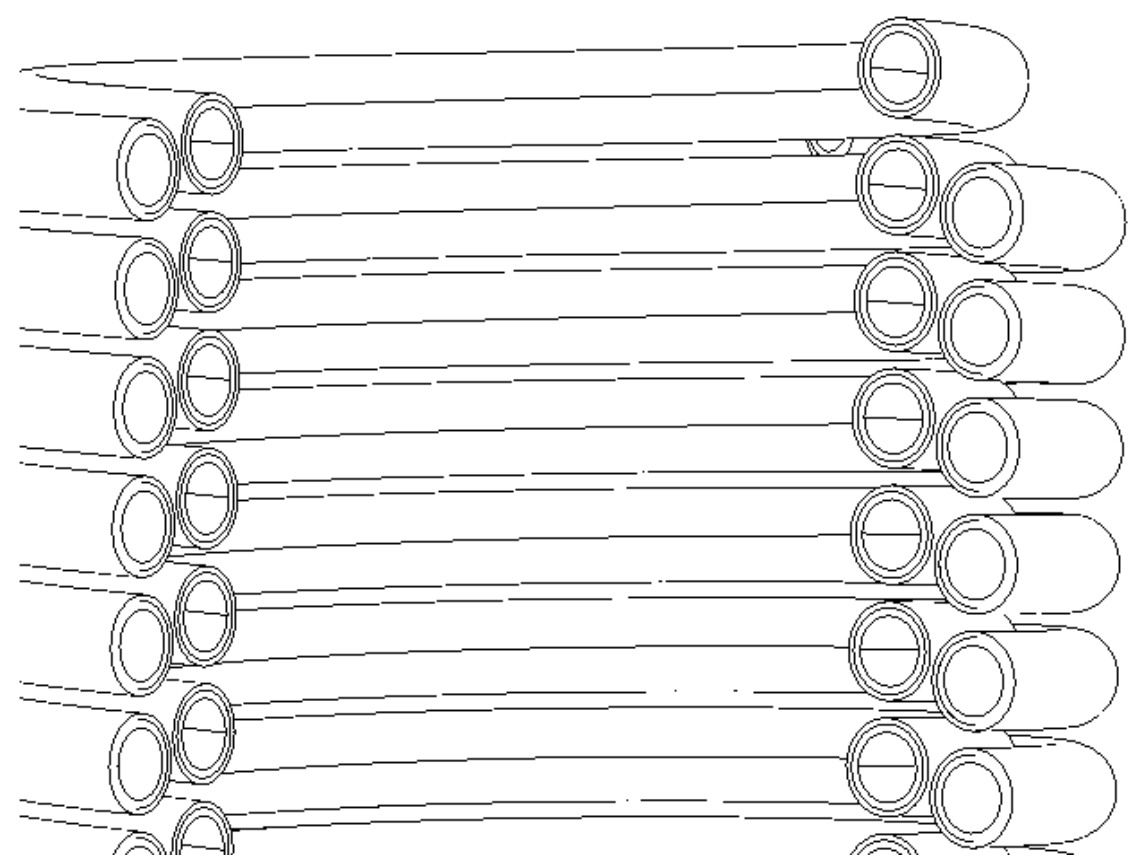

Figure 38 Illustration of polyethylene coated copper heat exchanger design

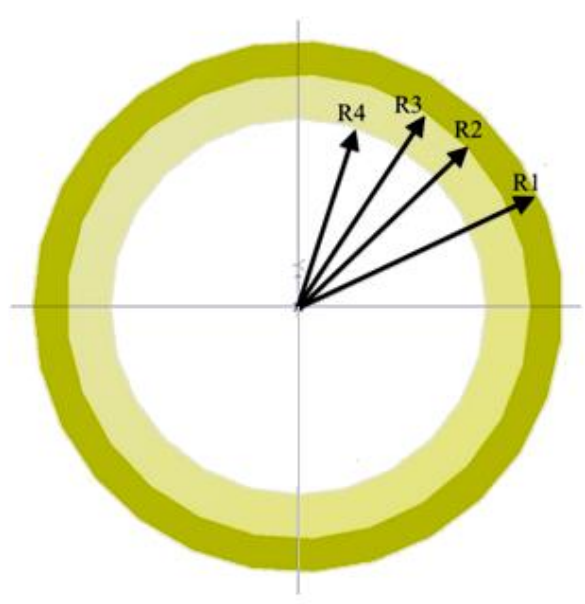

Figure 39 Side view of polyethylene coated copper tubing 
Table 5 Tubing Specifications

\begin{tabular}{|c|c|c|c|c|c|}
\hline $\begin{array}{c}\text { Material of } \\
\text { Construction }\end{array}$ & OD (mm) & ID $\mathbf{( m m )}$ & $\begin{array}{c}\text { Wall } \\
\text { Thickness } \\
(\mathbf{m m})\end{array}$ & $\begin{array}{c}\text { Thermal } \\
\text { Conductivity } \\
\text { (W/mK) }\end{array}$ & $\begin{array}{c}\text { Tubing Side } \\
\text { View }\end{array}$ \\
\hline Nylon-12 & 12.0 & 9.00 & 3.00 & 0.25 \\
\hline $\begin{array}{c}\text { Cool Polymer } \\
\text { RS1486 }\end{array}$ & 12.0 & 9.00 & 3.00 & 1.6 & \\
\hline $\begin{array}{c}\text { Polyethylene } \\
\text { coated copper }\end{array}$ & 9.525 & 8.00 & 0.762 & $0.32 / 388$ \\
\hline Copper & 12.0 & 9.00 & 3.00 & 388 & \\
\hline
\end{tabular}

Calculating the overall heat transfer coefficient, showed the polyethylene coated copper tubing's performance to be similar to its competitor, RS 1486 and superior to its predecessor, Nylon-12.

\section{Material's Effect on Overall Heat Transfer Coefficient}

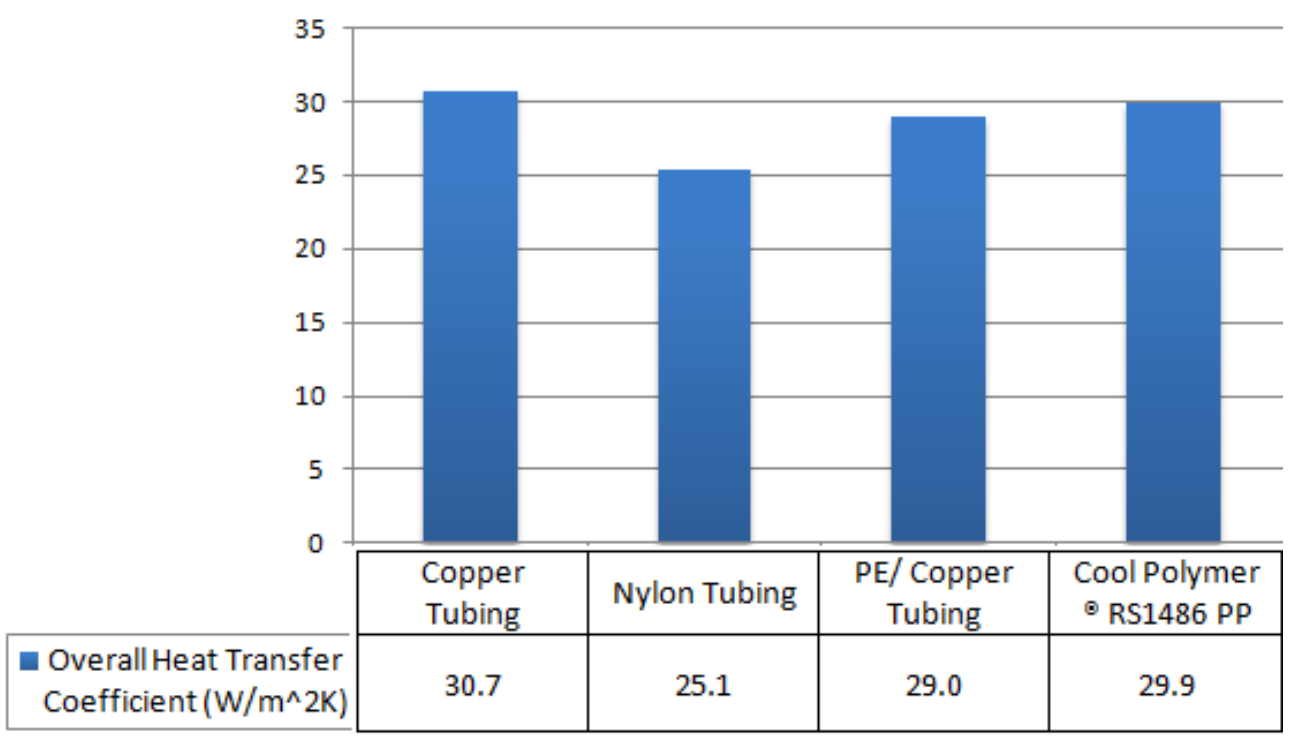

Figure 40. Overall heat transfer coefficient trends 
Based on these calculations, the polymer covered copper coil appears to be an attractive alternative. In this project a prototype heat exchanger was built and tested with this material. With this prototype, uniformity of spacing between the loops of the coil was not acceptable simply due to the construction method used and overall heat transfer performance was not as good as expected. This is not considered useful data and so not included here. The most important "lesson-learned" is that physical construction details to ensure uniformity of spacing with this design are critical.

\section{Discussion of Cost of Conductive Polymer Heat Exchangers}

The cost of a condensing heat exchanger made from thermally conductive polymers relative to metal alloys is difficult to estimate because of the many factors involved. In this section, the basic factors which affect cost are presented and discussed.

For metallic condensing economizer heat exchangers 316L alloy is commonly used. The bulk price of this alloy is estimated at $\$ 130 / \mathrm{lb}$. Some condensing boilers designed for oil-firing use 904L alloy and here the price can be significantly higher, $\sim \$ 3.00$ per pound. Prices of course depend on quantity purchased, shape, and finish options.

For a thermally conductive polymer heat exchanger the basic components can first be considered relative to cost. The bulk price of the polymer matrix can be estimated at $\$ 0.80 / \mathrm{lb}$. The cost of the thermally conductive filler depends very strongly on the filler used. Graphite powder can be estimated at $\$ 4 / \mathrm{lb}$. Boron nitride, commonly used as a filler is much higher in cost $\sim \$ 35 / \mathrm{lb}$. However, additional factors such as coupling agents can make the cost of a composite considerably higher than the simple cost of the components and commercial composites are typically proprietary. One manufacturer of thermally conductive polymer composite feed material offered the estimated price of $\$ 7.00 / \mathrm{lb}$. in large commercial quantities. In small quantities the price could be significantly higher.

The density of polymer composites is much lower than that of alloys and cost on a per-unit-mass basis can be converted to a per-unit-volume basis. This is done in Table 1, below, with different assumptions about cost. The density of the metal alloy is assumed fixed at $7,990 \mathrm{~kg} / \mathrm{m}^{3}$ and the density of the polymer composite is assumed fixed at $1,240 \mathrm{~kg} / \mathrm{m}^{3}$.

Table 6 Comparison of the Cost per Unit Volume of Polymer Composites and Alloys

\begin{tabular}{|l|l|l|}
\hline Material & Cost $-\$ / \mathrm{lb}$ (assumed) & Cost $-\$ / \mathrm{ft}^{3}$ \\
\hline Alloy & 1.50 & 748. \\
\hline Alloy & 3.00 & $1,495$. \\
\hline Composite & 7.00 & 541. \\
\hline Composite & 15.00 & $1,160$. \\
\hline Composite & 20.00 & $1,547$. \\
\hline
\end{tabular}


Consideration must also be given to the tensile strength of the polymer composites vs that of the alloys which can lead to thicker sections and more volume required for the composites. The nominal tensile strength of alloy $904 \mathrm{~L}$ is $88,000 \mathrm{psi}$ and the manufacturer of one commercial thermally conductive polymer provides a value for tensile strength of 70,000 psi. The additional volume required due to this difference in tensile strength is a function of the geometry but roughly $20 \%$ additional volume can be estimated.

The cost of the complete heat exchanger will be dependent on the design construction details and quantity. The production cost with the polymer composite can be low if an injection molded construction is used. The also provides the advantage of being able to design into the mold some mechanical features such as attachment points. However, there is a significant initial capital investment for the mold which would not be justified unless the production quantiles were large. In smaller quantities extruded designs, machined blocks, or assemble basic sections could be considered.

The cost of the composite will depend on the required thermal conductivity and this, again, connects directly to the design. The thermally conductive composite we have been using in this analysis has a nominal conductivity of $10 \mathrm{~W} / \mathrm{mK}$. However, our analysis has shown that at a thermal conductivity of $1.5-2 \mathrm{~W} / \mathrm{mK}$, the overall heat transfer performance is similar to that of a stainless steel construction. Lower cost fillers and lower volumetric fill fractions could help lower the cost.

In discussions with conductive composite filler and resin manufacturers, it is clear that there is an optimization of material and process selection that is needed to achieve the lowest possible cost. This level of interaction is difficult to achieve in the context of an R\&D project. It would be possible with a manufacturer directly involved in a specific product project. To illustrate, during this project thermally conductive polymer resins were purchased at $\$ 35 / 1 b$.

Overall, from this cost study, it seems that there is a potential for an optimized thermally conductive polymer heat exchanger to be similar in cost to an alloy heat exchanger but it may be difficult to achieve a strong cost advantage. It should be noted that the far greater resistance to corrosion in the polymer composite case may still provide an advantage for this option.

\section{Conclusions}

The heat transfer analysis work, confirmed by boiler testing, showed that a polymer heat exchanger, even with a lower thermal conductivity can achieve similar overall heat transfer performance. Because the critical heat transfer resistance is in the gas phase film, the overall performance is not significantly affected by the lower thermal conductivity. However, the lower thermal conductivity of the polymer will lead to a higher surface temperature on the gas side of the heat exchanger. This will lead to lower condensation rates. In an oil-fired heating system, 
where the flue gas water vapor content is relatively low, the latent heat contribution to the overall heat recovery is also low. In a gas-fired heating system, where the flue gas water vapor content is significantly higher, the polymer heat exchanger may be less attractive.

In this work the construction of the heat exchanger was based on an extruded, coiled design. While this design provides a very compact heat exchanger with low pressure drop, the extrusion process and coiling of the tube was found to be difficult because of the filler materials. It was achieved but future consideration to alternative construction methods may be appropriate. A significant advantage of the extruded and coiled tube is minimal physical connections or seals.

The coupon studies demonstrated minimal detectable impact on the polymer materials of the acidic flue gas condensate. 
